\title{
Texture enhancement during grain growth of magnesium alloy AZ31B
}

\author{
J.J. Bhattacharyya ${ }^{1}$, S.R. Agnew ${ }^{1} *$, G.Muralidharan ${ }^{2}$
}

1. Materials Science and Engineering Department, University of Virginia, Charlottesville, VA 22904, U.S.A.

2. Materials Science and Technology Division, Oak Ridge National Laboratory, Oak Ridge, TN, 37831, U.S.A.

\begin{abstract}
The microstructure and texture evolution during annealing of rolled $\mathrm{Mg}$ alloy, $\mathrm{AZ31B}$, at temperatures ranging from 260 to $450{ }^{\circ} \mathrm{C}$ is characterized, and a grain growth exponent $n=5$, indicating inhibition of grain growth is observed. Broadening of the normalized grain size distributions, which indicates abnormal grain growth, was observed at all temperatures investigated. It is shown, using a Zener type analysis for pinning of grain boundaries by particles, that impurity-based particles are responsible for grain growth inhibition and abnormal grain growth. The strong basal texture which develops during rolling of the $\mathrm{Mg}$ alloy, resulting in an initial peak intensity in the (0002) pole figure of 9 multiples of a random distribution (MRD), increases to $\sim 15 \mathrm{MRD}$ during annealing at 400 and $450{ }^{\circ} \mathrm{C}$. Moreover, a specific texture component $\{0001\}\langle 11 \overline{2} 0\rangle$ is observed in the orientation distribution (OD), which increases from $10 \mathrm{MRD}$ to $23 \mathrm{MRD}$ at $400^{\circ} \mathrm{C}$. It is hypothesized that the anisotropic grain boundary properties (i.e. low angle boundaries have low energy and mobility) are responsible for the texture strengthening. Additionally, Electron Back Scatter Diffraction (EBSD) reveals the recrystallized microstructure to contain a significant number of boundaries with $\sim 30^{\circ}$ misorientation about the $<0001>$ direction, and this boundary type persists throughout most annealing treatments explored.
\end{abstract}

*Corresponding author: agnew@virginia.edu 
Keywords: grain size distribution, grain boundary, orientation distribution, abnormal grain growth, anomalous grain growth

\section{Introduction}

Rolled magnesium $(\mathrm{Mg})$ alloy sheets typically exhibit tension-compression yield strength asymmetry due to the presence of a strong basal texture with the c-axis of the crystal parallel to the through thickness direction of the sheet. This contributes to poor cold formability and hinders broader application of these lightweight materials. For some applications, thermo-mechanical processing is followed by various annealing schedules in order to obtain a recrystallized microstructure, to alter the texture or to relieve residual stresses. In the case of $\mathrm{Mg}$ alloys, it has been found that the basal texture is retained after recovery and recrystallization annealing [1]. In this way, hexagonal close packed (hcp) Mg alloys are more similar to many body centered cubic (bcc) alloys than they are to face centered cubic (fcc) alloys, since the latter frequently undergo strong crystallographic texture evolution during recrystallization [2]. Even though a considerable amount of research has been devoted to developing an understanding of the recrystallization behavior of Mg alloys e.g., [3], little work has been done to explore the effect of grain growth annealing on microstructure and texture evolution.

This paper documents the kinetics of grain size evolution during annealing, including the abnormal grain growth phenomena that has been observed in this alloy [4] and the texture evolution during grain growth. Subsequently, the possibility that these two phenomena (anomalous grain growth and texture strengthening) are correlated is explored. Finally, the role of grain boundary character distribution (GBCD) on the mechanism of texture evolution is considered. AZ31B has been chosen for this study in order to assist in the practical application of 
the findings. In such a commercial alloy, complicating factors threaten to obscure the desired information (e.g., the solute elements and second phase particles will be shown to play an important role in determining grain growth behavior). However, it has proven possible to parse conclusions from the observations.

\section{Experimental methods}

\section{1. Material, heat treatment and metallography}

The material investigated was part of a larger study focused on the effect of shear rolling on the microstructure and properties of magnesium alloys. Alloy AZ31B sheet of thickness 1.52 mm was obtained from Magnesium Elektron North America and shear rolled at Oak Ridge National Laboratory with both the rolls and the metal held at $200{ }^{\circ} \mathrm{C}$. The details of the processing is described elsewhere [5]. One conclusion of that broader study was that the range of shear rolling conditions explored does induce quantitative changes in the resulting basal texture of the sheet, such as a slight asymmetric tilting of the basal poles from the sheet normal direction (ND) toward the rolling direction (RD) and broadening of the basal peak toward the transverse direction (TD), which induces some effect on the anisotropy of properties between the rolling and transverse directions [5]. However, the qualitative appearance of the textures is largely unchanged. As such, the fact that the material was shear (rather than conventionally) rolled is not viewed as an important aspect in what follows.

Samples were then heat-treated at temperatures ranging from 260 to $450{ }^{\circ} \mathrm{C}$ for durations ranging from 1 to $604,800 \mathrm{~s}$ (10080 min, 7 days) in order to produce samples of varying grain size $(5-50 \mu \mathrm{m})$. The short duration anneals $(\mathrm{t}<960 \mathrm{~s}(16 \mathrm{~min}))$ were performed in a $\mathrm{KNO}_{3}$ salt bath. For all other annealing durations, an air furnace was used. All the samples were quenched in room temperature water after annealing. For optical and Scanning Electron Microscopy 
(SEM) based metallographic examination, the samples were ground to the sheet mid-plane, cold mounted in epoxy, and mechanically ground up to 1200 grit SiC paper followed by 3 and $1 \mu \mathrm{m}$ oil based diamond paste and finally with $0.06 \mu \mathrm{m}$ colloidal silica polishing. The specimens were etched in an acetal - picral solution (4.2 g picric acid, $10 \mathrm{ml}$ acetic acid, $70 \mathrm{ml}$ ethanol, and $10 \mathrm{ml}$ water) for $5-10 \mathrm{~s}$.

The grain size is measured from optical micrographs using the lineal intercept method in MATLAB toolbox Linecut, following the ASTM standard E112 -96 [6]. The measured grain sizes were plotted as histograms using Origin software, with a bin size of $1 \mu \mathrm{m}$, and then fitted with the log normal distribution to obtain the arithmetic mean grain size. The data were then normalized by this mean and plotted as histograms with bin size $0.2 \mu \mathrm{m}$ and then fitted with a Gaussian distribution to obtain the breadth of the normalized distribution. During normal grain growth the breadth of this distribution remains invariant [7]. Any evolution of this breadth is used as an indicator of abnormal grain growth [8,9].

\section{2. Texture measurements}

The texture was measured on the as received sheet and after all annealing heat treatments. The measurements were made on the sheet mid-plane of the sheets, to obtain the bulk texture and avoid any surface effects such as a near-surface gradient in texture which has been observed previously [10]. The measurements were made using a Panalytical X'pert Pro multi-purpose diffractometer (MPD) with $\mathrm{Cu} \mathrm{K \alpha}$ radiation operating at $40 \mathrm{kV}$ and $45 \mathrm{~mA}$, in Schultz reflection method [11], to minimize defocusing at higher $\chi$ tilts. An incomplete $\left(\chi=0-80^{\circ}\right)$ basal (0002) pole figure was obtained for all annealing conditions. An experimental defocusing curve was obtained from a randomly textured $\mathrm{Ti}$ powder sample. Background subtraction, defocusing correction, and normalization were carried out using MATLAB toolbox MTeX. The raw data 
was smoothed using a Gaussian filter of $5^{\circ}[12]$ in order to get rid of spurious intensity spikes.

For selected annealing conditions, the (10 $\overline{1} 0),(0002)$, and (10 $\overline{1} 1)$ incomplete pole figures were collected and the texture data were analyzed using MTeX to generate complete orientation distributions (ODFs) and full pole figures. In MTeX, the reference frame was set as Xlla, Yllb* and Zllc, such that the RD is aligned with the $<11 \overline{2} 0>$ of the crystal for the Euler angles $\left(0^{\circ}, 0^{\circ}\right.$, $\left.0^{\circ}\right)$

\section{3. Second phase particle characterization}

To evaluate the evolution of the second phase particles during annealing, the volume fraction and the particle size were measured using a JEOL 6700 Scanning Electron Microscope (SEM) in secondary electron (SE) and back-scattered electron (BSE) mode. The composition was obtained from energy dispersive spectroscopy (EDS) together with the Oxford-Pgt Spirit EDS software. The particle size was measured using a lineal intercept technique from the SEM BSE images. The volume fraction was obtained based on the stereological concept [13] that in a randomly obtained planar section, the area fraction occupied by the particles is equal to the volume fraction of the particles. In order to obtain the area fraction, multiple (6-8) appropriately thresholded SEM images were obtained using analysis software, ImageJ.

\section{4. Orientation imaging maps}

After carrying out standard metallographic preparation as described above, the samples chosen for electron backscattered diffraction (EBSD) were cleaned with a plasma etching and coating system (PECS) to remove the deformation layer and facilitate indexing. EBSD was performed within a FEI Quanta 200FEG SEM equipped with an EDAX/TSL System with Hikari EBSD Detector. The objective of these experiments was to determine the character of the grain boundaries present in the system and to obtain the grain boundary misorientation distribution. 
The electron microscope was operated at $20 \mathrm{kV}$ with a working distance of $15 \mathrm{~mm}$ at a magnification of 500X. The step size and the spot size during EBSD data collection was $0.5 \mu \mathrm{m}$ and 5.5 (corresponding to a beam current of $11 \mathrm{nA}$ ), respectively. The confidence index (CI) of the diffraction patterns was between $0.5-0.7$, indicating the quality of pattern identification was $72-87 \%$ for the samples examined.

\section{Results}

\section{1. Characterization of as rolled AZ31B sheet}

The microstructure of the as-received sheet material is relatively fine grained and has few deformation twins (Fig. 1a). The grain size distribution is observed to be log normal (Fig. 1b), with a mean lineal intercept grain size of $5.3 \mu \mathrm{m}$, and the width of the initial normalized grain size distribution is 0.55 (Fig. 1c). The fine grains and low twin density are evidence of dynamic recrystallization (DRX) during hot rolling of the sheet. In addition, a few fine second phase particles and some larger $(\sim 2 \mu \mathrm{m})$ particles, revealed to be Al-Mn compounds by SEM-EDS, are

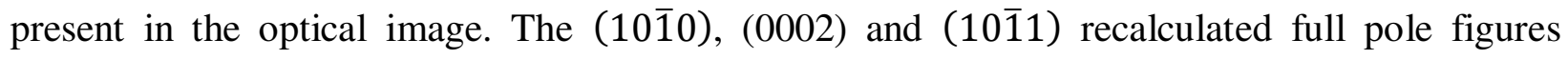
obtained from the orientation distribution of the as-received sheet are shown in Figure 1d. From these pole figures, it is seen that the (0002) basal poles are nearly aligned with the sheet normal direction. The maximum intensity is $\sim 9$ multiples of a random distribution (MRD) in the (0002) pole figure, with a slight spread towards the rolling direction, in accordance to previous observations of shear rolled $\mathrm{Mg}$ alloy sheets [16]. Notably, the (1010) pole figure exhibits near radial symmetry, but complete orientation distribution analysis (shown below) will reveal that there is a slight preferred orientation.

\section{2. Grain growth kinetics, size distributions, and abnormal grain growth.}


Figure 2a presents a plot of mean grain diameter against annealing time for all temperatures investigated in this study. The data has been fitted with the grain growth equation:

$$
D^{n}-D_{0}^{n}=k t
$$

where,

$$
k=k_{0} \exp \left(-\begin{array}{c}
Q \\
R T
\end{array}\right)
$$

The initial grain size, $D_{0}$, rate constant, $k$, and grain growth exponent, $n$ were all free parameters in the fitting. $D_{0}$ was fitted because it must be admitted that recrystallization may not be complete after warm rolling, and the grain size after the completion of recrystallization may be temperatures dependent. Of interest in this study is the initial grain size when only grain growth itself is occurring. The values of the initial fitting parameters are shown in Table 1. After this initial round of fitting was performed, it was noted that the average grain growth exponent $n$ $\sim 5$ for $300,340,400$ and $450{ }^{\circ} \mathrm{C}$. (Due to limited data collected at $260{ }^{\circ} \mathrm{C}$, these were not considered for evaluating $n$.) For further analysis, all of the kinetic data were refitted using a fixed value of $n=5$, in order to determine the temperature dependence of the values $D_{0}$ and $k$. This latter step enabled $k$ to be determined at each of the 5 temperatures examined. The final fitting parameters (Table 2) reveal that the selection of $n=5$, actually improves the uncertainties and goodness of fit metrics. Finally, a plot of the logarithm of the rate constant $k$ against $1 / T$ is shown in Figure 2b. A linear fit and the adjusted $R^{2}$ value of the data suggests that the process is indeed thermally activated, with a single activation energy $Q=115 \mathrm{~kJ} / \mathrm{mol}$, over the entire temperature range examined (homologous temperatures of $0.58-0.78$ ).

Figures 3-5 show the optical micrographs and the plot of the normalized grain size distribution for some samples annealed at 300,400 and $450{ }^{\circ} \mathrm{C}$, respectively. The short duration anneal at 300 and $400{ }^{\circ} \mathrm{C}$ leads to a uniform grain size distribution. No abnormally large grains are visible. This trend is observed up to at least $259,200 \mathrm{~s}$ ( 3 days) of annealing in case of $300{ }^{\circ} \mathrm{C}$ 
and up to at least $64,800 \mathrm{~s}$ (1080 min) in case of $400{ }^{\circ} \mathrm{C}$. Longer duration anneals do result in some abnormally large grains. However, the grain size distribution remains log normal (not bimodal), and the breadth of the normalized grain size only increases slightly. After annealing at $300{ }^{\circ} \mathrm{C}$ for $604,800 \mathrm{~s}$ (7 days), the grain size is only slightly increased and the grain size distribution remains log normal (note the consistently low $\chi^{2}$ values) with a breadth that is only slightly larger, suggesting that abnormal grain growth occurs due to normal grain growth restriction [14-16].

Unlike the 300 and $400{ }^{\circ} \mathrm{C}$ heat treatments, the $450{ }^{\circ} \mathrm{C}$ short duration anneal results in a heterogeneous microstructure with almost equal area fraction of large and very fine grains. Nevertheless, the grain size distribution remains log normal and the breadth of the distribution is similar to that of observed at $300{ }^{\circ} \mathrm{C}$. In no condition examined were a few grains observed to grow many times larger than the mean grain size. Rather, a very slight "shoulder" is sometimes observed on the high side of the grain size distribution (Figs. 3-5).

A plot of the variation of width of the normalized grain size distributions with logarithm of annealing time is presented in Figure 6 which summarizes the data for $340-450{ }^{\circ} \mathrm{C}$. The breadth of the distribution does not change significantly for any of the annealing conditions investigated, rather it oscillates. This observation suggests that when some grains begin to grow much faster than the others, thereby broadening the distribution, the finer grains quickly catch up and prevent the distribution from becoming bimodal. Hence, the abnormal grains appear temporarily and persist until the matrix grains catch up. This indicates the transient nature of the abnormal grain growth $[8,9,17,18]$. This type of observation has been previously observed experimentally [19] as well as during simulations [8].

\section{3. Texture evolution during grain growth}


The variation of (0002) peak texture strength as function of the logarithm of annealing time is shown in Figure 7a-c. Multiple points at a given time indicate multiple texture measurements on the same sample, as a means of increasing the grain statistics of the measurements and as an assessment of uncertainty. The red points in the plot correspond to instances where complete ODFs were computed and the intensity determined from full, recalculated (0002) pole figures, rather than the incomplete pole figures used to develop the data represented by black squares. Figure $7 d$ shows the value of the peak ODF intensity as function of the logarithm of annealing time. It is seen that the texture strength remains more or less constant at $300^{\circ} \mathrm{C}$. At $400^{\circ} \mathrm{C}$, the texture strength shows steady rise up to about $500 \mathrm{~min}$ followed by a transient decrease and then rapid increase. It is noted that there is some scatter in the data as evident in Fig. 7 a-c. Therefore, it is possible that the dip in texture strength observed at about $1000 \mathrm{~min}$ is due to sample-to-sample variation, and there is in fact a monotonic increase in the texture strength as indicated by the dotted line in the Fig $7 \mathrm{~d}$. At $450^{\circ} \mathrm{C}$, the texture intensity rises steadily up to $3600 \mathrm{~s}$ (60 $\mathrm{min})$ then remains essentially constant.

In order to further characterize the texture, the $\varphi 2=0^{\circ}$ section of the ODF of the material in the as received and some of the annealing conditions at 300,400 and $450{ }^{\circ} \mathrm{C}$ is shown in Figure 8a-f. The $\{0001\}\langle 11 \overline{2} 0\rangle$ recrystallization component (henceforth denoted as "R") corresponds to Euler angles $\varphi 1=0^{\circ}, \varphi=0^{\circ}, \varphi 2=0^{\circ}$ and $60^{\circ}$ and the $\{0001\}\langle 10 \overline{1} 0\rangle$ deformation component (henceforth denoted as "D") which forms due to prismatic slip activity during deformation [20], has Euler angles of $\varphi 1=30^{\circ}, \varphi=0^{\circ}, \varphi 2=0^{\circ}$ and $60^{\circ}[1,21]$. It is to be noted that, after analyzing the ODF plots for the complete range of $\varphi 1$ i.e. $0^{\circ} \leq \varphi 1 \leq 360^{\circ}$, orthotropic symmetry was imposed and $\varphi 1$ is plotted in the range $0^{\circ} \leq \varphi 1 \leq 90^{\circ}$. 
It can be seen that the $\mathrm{R}$ component has a slight preference over the $\{0001\}<10 \overline{1} 0>$ component in AR material (Fig. 8a). This was not evident in the pole figure shown in Fig. 1d. This suggests that this particular component is already present in the starting microstructure and does not nucleate during the grain growth process. Fig. $8 \mathrm{~b}$ shows the same ODF section for a sample annealed at $300{ }^{\circ} \mathrm{C}$ for $604,800 \mathrm{~s}$ (7 days). After 7 days of annealing, it seems that the $\mathrm{R}$ component only slightly increases as compared to the other. Figures 8c and d show ODF sections for samples annealed at $400{ }^{\circ} \mathrm{C}$, for $3600 \mathrm{~s}$ (60 min) and 604,800 s (7 days), respectively. It can be seen that up to 60 min both components persist and the distribution of the intensities remain homogeneous, after which the $\mathrm{R}$ component takes off, rapidly consuming the $\mathrm{D}$ component. In case of $450{ }^{\circ} \mathrm{C}$ annealing, shown in Figures 8e and f, the $\mathrm{R}$ component has grown preferentially within $3600 \mathrm{~s}(60 \mathrm{~min})$ of annealing and continues to grow. This observation suggests that the growth rate of the $\mathrm{R}$ component is faster at $450^{\circ} \mathrm{C}$ than at $400^{\circ} \mathrm{C}$, as one would expect because of faster kinetics. It is worth mentioning that the average basal pole intensity levels are very similar at these two temperatures, and thus this transition would be impossible to capture only from the basal pole intensity. On prolonged annealing at both $400^{\circ} \mathrm{C}$ and $450^{\circ} \mathrm{C}$, the $\{0001\}\langle 11 \overline{2} 0\rangle$ component increases while the $\{0001\}<10 \overline{1} 0>$ component decreases leading to the observed hexagonal symmetry in the pole figure, such as the one shown in Figure 9.

It was initially hypothesized that the observed abnormal grain growth may be due to this initial texture and/or responsible for the texture evolution, since one explanation for anomalous grain growth is grain boundary energy anisotropy. The presence of texture means that there is an initial preference for certain boundaries; hence some grain orientations may grow at the expense of others. By comparing the evolution of the breadth of the normalized distribution (Fig. 6) and texture strength (Fig. 7) suggests that abnormal grain growth has a little or no influence on the 
texture evolution. Possible explanations for the abnormal grain growth were sought in terms of particle microstructure evolution and discussed below.

\section{4. SEM based characterization of second phase particles.}

From optical micrographs, it is seen that second phase particles ranging from sub-micron size to a few microns are present, at all annealing conditions. The particles coarsen and it seems that some grain boundaries are pinned by fine particles. As an example, optical micrographs of samples annealed at $450{ }^{\circ} \mathrm{C}$ for $3600 \mathrm{~s}$ (60 min) and 453,600 s (5.25 days) are shown in Figure $10 \mathrm{a}$ and $\mathrm{b}$. It is evident from these micrographs that a strong local curvature develops when the grain boundary interacts with a particle. Given the observation of abnormal grain growth as indicated by the increase in the breadth of the normalized distribution, it seems possible that reduced Zener pinning due to particle coarsening could be responsible. On further annealing for $604,800 \mathrm{~s}$ (7 days), there is a considerable increase in the number of fine particles in the microstructure. In order to study the influence of these particles on grain growth, their size, volume fraction and composition were examined using SEM. It is admitted that this approach is likely to underestimate the volume fraction and overestimate the average particle size, relative to that which would be assessed by transmission electron microscopy. Two distinct size classes of particles were observed in the microstructure. The larger particles have a faceted morphology and are about 1-10 $\mu \mathrm{m}$ in size. Besides these, there are also fine particles present in the microstructure having a plate morphology and they are of the size range of $<1 \mu \mathrm{m}$.

Energy dispersive x-ray spectroscopy (EDS) data collected from these particles revealed the larger ones to be Al-Mn based particles and their presence in the microstructure is consistent with observations in the literature [22,23]. The exact compositions were not determined but it has been previously determined that different $\mathrm{Al}-\mathrm{Mn}$ compounds like $\mathrm{Al}_{8} \mathrm{Mn}_{5}$ and $\mathrm{Al}_{11} \mathrm{Mn}_{4}$ are 
generally present in the microstructure of this alloy [24]. There are also Mg-Al based particles observed at 400 and $450{ }^{\circ} \mathrm{C}$, which are most probably $\mathrm{Mg}_{17} \mathrm{Al}_{12}$ phase, again consistent with the existing literature $[15,16]$. The finer particles observed have a size of around $100 \mathrm{~nm}$ and are impurity based particles containing elements such as $\mathrm{Ca}, \mathrm{Fe}, \mathrm{Si}$, and Ti. Again as before, the exact compositions were not determined since this was not of primary interest for this study. From the SEM micrograph Fig.10e, it can be seen that a large fraction of the second phase particles are either plate or rod shaped. It is noted that such non-spherical particles can interact very differently with the grain boundaries as compared to the spherical ones [8]. The particle size and volume fraction evolution during annealing is shown in Figure 11. These data are incorporated into a Zener pinning analysis.

\section{5. 1. Grain boundary character distribution (GBCD)}

EBSD was used to determine the orientation of the grains and the disorientations of the boundaries surrounding them. In order to present the grain boundary character graphically, the boundaries were color-coded according to their misorientation. The EBSD maps are presented as a normal direction (ND) inverse pole figure (ND-IPF) map, for samples annealed at $300^{\circ} \mathrm{C}$ for 60 $\mathrm{s}(1 \mathrm{~min})$ (Figure 12a) with the experimental correlated and uncorrelated grain boundary misorientation distribution (GBMD) along with the calculated distribution for a randomly oriented polycrystal (Figure 12b). From the ND-IPF map, it can be seen that the majority of the grains have their $\mathrm{c}$ axes parallel to the ND of the sheet (i.e. the grains are generally reddish colors), which is expected because of the given basal texture. The GBMD shows a higher fraction of grain boundaries with misorientation $<50^{\circ}$, and a lower fraction of boundaries with $>50^{\circ}$ misorientation than that for a randomly oriented sample. It is to be noted that the deviation in case of the fraction of LAGBs $\left(<15^{\circ}\right)$ is much higher as compared to the deviation from $35-50^{\circ}$ 
misorientation. Another difference from the random distribution is the presence of a large peak at $30^{\circ}$ misorientation and a much smaller but distinct peaks at a misorientation around $75^{\circ}$ and $\sim$ $85^{\circ}$ which is associated with the extension twins which persist because of the low energy twin boundaries [25].

A similar set of maps for annealing at $300^{\circ} \mathrm{C}$ for $18,000 \mathrm{~s} \mathrm{(300} \mathrm{min)} \mathrm{is} \mathrm{shown} \mathrm{in} \mathrm{Figure}$ $12 \mathrm{c}$ and $\mathrm{d}$. From the GBMD plot, it is seen that the fraction of the LAGBs and HAGBs remains essentially the same while the $30^{\circ}$ misorientation peak strengthens. It is to be admitted that after 1 min of annealing at $300^{\circ} \mathrm{C}$, recrystallization may not be complete, so the strengthening of the $30^{\circ}$ misorientation peak during annealing at that temperature may be related to the completion of recrystallization [1]. Note that the $75^{\circ}$ peak also remains distinct after such annealing. EBSD maps along with plots of GBMD from samples annealed at $450^{\circ} \mathrm{C}$ for $240 \mathrm{~s}(4 \mathrm{~min}$ ) (Fig. e and f) and 79,200 s (1320 min) (Fig. $g$ and h) reveal that the fraction of LAGBs remains higher and that of HAGBs lower than the random distribution for high temperature annealing also. It is interesting to note that the peaks at $30^{\circ}$ and $75^{\circ}$ disorientation persist although the amount of it has decreased, after such long duration anneals at high homologous temperatures. This suggests that this is a low energy "special" boundary similar to the $\Sigma 3^{\mathrm{n}}$ twin boundaries in face centered cubic crystals. A distinct difference, however, is the lack of preference for a particular habit plane. Note that the $30^{\circ}$ boundaries are not particularly flat or faceted at a level which is observable in the EBSD maps. Rather, they adopt curvature in response to torques at the grain boundary triple points as would be expected for more general boundaries. It is to be noted that during grain growth, whether a grain grows or shrinks depends on the nature of the grain boundaries surrounding it, and these migrate towards its centre of curvature. Hence, after longer duration anneals, (Fig. $12 \mathrm{~g}$ ) the grains having an off-basal orientation have less than 6 sides with 
convex (bulging outwards) grain boundaries indicating that they are getting consumed at the cost of their neighboring grains which are typically closer to the basal orientation. In all cases, the $30^{\circ}$ peak appears also, albeit less dramatically, in the uncorrelated distributions. It is to be noted that for the $450{ }^{\circ} \mathrm{C} 1320 \mathrm{~min}$ anneal case, the uncorrelated and correlated distributions almost overlap, which suggests the appearance of the peak is more associated with the texture than the grain boundary character.

\section{5. 2. Identification of special boundaries}

Recent molecular dynamics (MD) simulations [25,26] have revealed the presence of various low energy grain boundaries in the high angle regime $\left(>15^{\circ}\right)$ in the hexagonal system. The complete list of these boundaries is summarized in Table 3, along with the previously identified $\sim 28^{\circ}[0001]$ perfect coincident site lattice (CSL) boundary [27,28]. The misorientation axis of the $\sim 30^{\circ}$ disoriented boundaries as observed in this study, is unequivocally identified to be $<0001>$ by plotting the axes of the angle/axis description with respected to the standard stereographic triangle of the hexagonal crystal. Such plots are shown in Figure 13a-d for annealing conditions of $300^{\circ} \mathrm{C} 60 \mathrm{~s}(1 \mathrm{~min}), 300^{\circ} \mathrm{C} 18,000 \mathrm{~s}(300 \mathrm{~min}), 450^{\circ} \mathrm{C} 240 \mathrm{~s}(4 \mathrm{~min})$ and $450^{\circ} \mathrm{C} 79,200 \mathrm{~s}$ (1320 $\left.\mathrm{min}\right)$ respectively, for all misorientation values presented in Table 3 . From these plots, it is evident that the $30^{\circ}<0001>$ boundary is present in all annealing conditions, although it has decreased after annealing at $450^{\circ} \mathrm{C}$ for $79,200 \mathrm{~s}(1320 \mathrm{~min})$. There is also presence of the $\sim 75^{\circ}\langle 11 \overline{2} 0\rangle$ disoriented boundary, which seems to persist after longer anneals.

\section{Discussion}

The results presented have revealed the basic grain growth kinetics, the evolution of the macro-texture and micro-texture $(\mathrm{GBCD})$ of the alloy, and the influence of second phase particles during grain growth heat treatment. The results are discussed in the following order: 


\section{1.) Grain growth Kinetics,}

2.) Normal and abnormal grain growth using Zener pinning analysis, and

3.) The mechanism of texture evolution during grain growth.

\section{1. Grain growth kinetics}

The theoretical model of Burke and Turnbull [29] predicts the grain growth exponent $n$ to be 2 . However, this is rarely observed experimentally in real materials. Their model assumes that the driving pressure is only due to the curvature of the boundary and there is no drag force acting on the boundary due to particles or solutes, and the grain boundary energies and mobilites are isotropic. These assumptions are clearly violated for the present alloy, due to the presence of the second phase particles, hence deviations from the theoretical value of $n$ is expected. The possible impact of anisotropy in boundary energy and mobility is enhanced due to the presence of a strong initial texture. The $n$ obtained in this study is equal to 5 and it is consistent with the values of $3.8-5$ previously obtained in the literature [30-32]. Such a high value of $n$ is suggestive of grain growth stagnation, which could be attributed to second phase particles exerting a drag force on the boundaries and pinning the microstructure. Indeed, the plots show that the $D$ vs. $t$ curves are quite flat after an initial jump in grain size at short durations. This is particularly evident at lower temperature, while the grain growth curves appear more parabolic as the temperature increases.

The apparent activation energy, $Q \sim 115 \mathrm{~kJ} / \mathrm{mol}$, determined from the rate constant, $k$, is intermediate to the value reported for grain boundary diffusion in $\mathrm{Mg}(92 \mathrm{~kJ} / \mathrm{mol})$ than the bulk diffusion in $\mathrm{Mg}$ (135 kJ/mol) [33]. Wang et al. [32] found the activation energy to be $110 \mathrm{~kJ} / \mathrm{mol}$ over a temperature range of $300-400{ }^{\circ} \mathrm{C}$. In $\mathrm{Al}$ alloys, the activation energy for grain growth was found to be $\sim 90 \mathrm{~kJ} / \mathrm{mol}$, which is close to grain boundary diffusion in $\mathrm{Al}(86 \mathrm{~kJ} / \mathrm{mol})$ but 
significantly lower than that for Al bulk diffusion (143.4 kJ/mol) [34]. Miao et al. [35] found the activation energy for grain growth in $\mathrm{Mg}$ alloy $\mathrm{AZ3} 1$ to be $81 \mathrm{~kJ} / \mathrm{mol}$, which is somewhat lower than that obtained in this study. The range of values obtained for this alloy suggests that activation energy may depend upon the composition (impurity levels) and the initial conditions (microstructure, vacancy content, etc.), particularly the fraction of LAGBs present since they have a much higher value of $Q$ as compared to HAGBs. It is generally observed that $Q$ for grain growth of metals falls between the activation energy for the bulk (upper bound) and the grain boundary diffusion (lower bound) [36]. Generally, the activation energy for grain growth is found to be closer to that of grain boundary diffusion [17,37]. In fact, MD simulations carried out by Yamakov et al. [38] have shown that in an impurity free microstructure, the activation energy for HAGB migration is equal to that for grain boundary diffusion, while for LAGBs the activation energy approaches that of bulk diffusion [17]. The presence of a strong texture at temperatures of $300-450{ }^{\circ} \mathrm{C}$ results in a large fraction of LAGBs in the microstructure as evident from the GBMD plots shown in Figure 12. Finally, it is noted that if solute drag is operative, the main alloying element, $\mathrm{Al}$, has very similar activation energy for interdiffusion in $\mathrm{Mg}$ as $\mathrm{Mg}$ self-diffusion [39].

\section{2. 1. Normal and Abnormal grain growth}

Abnormal grain growth can be qualitatively described as the sudden appearance of unusually large grains in a matrix of uniform grains, and by invoking theoretical concept of loss of self-similarity, it can quantitatively be distinguished from normal grain growth by increase in the breadth of the grain size distribution normalized by the mean grain size $[8,9,14,18,40]$. It is to be noted that in the present study, no "island grains" having a grain size many times larger than the mean, were observed. However, the grain size distribution appeared heterogeneous and the 
width of the normalized distribution varied with annealing. This is distinct from the observations in an earlier study on pure $\mathrm{Mg}$ [41], where large abnormal grains of $\sim 250 \mu \mathrm{m}$ were observed after annealing for $1 \mathrm{~h}$ at $400{ }^{\circ} \mathrm{C}$. The abnormal grain growth as described in this study refers to the increased breadth of the normalized distribution. The different behavior of this alloy, as compared to pure $\mathrm{Mg}$, is attributed to the presence of second phase particles and a Zener pinning model has been used to explain this behavior, later in this section.

It has been shown theoretically [42] as well as by Monte Carlo computer simulations [8] that abnormal grain growth is not possible in an ideal microstructure where grain growth is driven only by capillary forces, with uniform grain boundary energies and mobilities. In such a case, a large grain would grow at a slower rate and would eventually be joined by the initially fine-grained matrix. However, conditions have been identified which do lead to abnormal grain growth. For example, it can result from the presence of strong initial crystallographic texture $[40,43]$. This is because grains of similar orientation have low angle (i.e. low energy and low mobility) boundaries between them resulting in reduced driving pressure and, thus, lower growth rates. Such abnormal grain growth can lead to pronounce changes in texture as well as altering the grain growth kinetics leading to a higher value of $n$ [44-47]. This possible connection between texture and abnormal grain growth was the original reason for initiating the present study, but as seen from the results presented in Figures 6 and 7, the observed increase in the breadth of the normalized grain size distribution and the texture strengthening is not temporally correlated. Furthermore, EBSD observations revealed abnormally large grains of both basal and non-basal (more random) orientations (e.g. Fig. 12 e). These observations suggest that abnormal grain growth has very little influence, if any, in dictating the texture strength and vice versa. Hence, it is hypothesized that the coarsening and interaction of the second phase particles with 
the grain boundaries may be responsible for the occurrence of abnormal grain growth in this alloy.

\section{2. 2 Comparison with Zener's model}

In fact, the most commonly cited explanation for abnormal grain growth is the coarsening of particles which pin the grain boundaries [16,17]. A classic example, which involves both of aspects (particles and texture), is the evolution of the Goss texture in Fe-Si steels. In this case, abnormal grain growth of Goss oriented grains occurs because MnS particles preferentially pin the boundaries of other grain orientations. This leads to a very sharp Goss texture, which is advantageous for transformer core applications $[48,49]$. The classic approach to understand the role of pinning particles on grain growth is to use Zener's original equation [50]:

$$
R_{c}=4 r / 3 f
$$

where, $R_{c}$ is the limiting grain radius, $r$ is the radius of the pinning particles and $f$, the volume fraction of the particles. The derivation of the above equation includes several simplifying assumptions such as spherical particles and grains, particles are randomly distributed with no preferential arrangement at grain boundaries. Although the particles present in the microstructure considered here are non-spherical, their distribution is random; hence this model has been applied here to obtain semi-quantitative comparison between observed and predicted grain sizes.

The mean lineal intercept grain sizes obtained in this study were converted to their 3D equivalent spherical diameter by multiplying by a factor of 1.5 [51]. Three annealing durations at temperatures of 300,400 , and $450{ }^{\circ} \mathrm{C}$ were considered and the critical radius was calculated. The results are tabulated in Table 4. It can be seen that Zener's model predicts a limiting grain size, suggesting that in spite of all the complications due to non-spherical particles and their coarsening and dissolution, the model does capture the essential physics. 
For the as received sheet as well as at $300{ }^{\circ} \mathrm{C}$, for all annealing durations, the experimentally obtained grain radius is much less than $R_{c}$, indicating that the pinning pressure is less than the driving pressure for grain growth, which leads to normal grain growth behavior. However, wider normalized distributions and "abnormal" grains are observed after longer duration anneals at $300{ }^{\circ} \mathrm{C}$. One possible explanation would be that in this simplistic Zener analysis, mean particle size is considered whereas in reality there is a size distribution and, thus, finer particles can lead to a smaller critical grain size leading to the occurrence of stagnation and abnormal grain growth. Stagnation is observed where the mean grain size increases from $\sim 13$ to $15 \mu \mathrm{m}$ upon annealing for $259,200 \mathrm{~s}$ to $604,800 \mathrm{~s}$ ( 3 to 7 days). When the $R_{c}$ is equal to the experimental grain size, the pinning pressure balances the driving pressure for grain growth and normal growth is inhibited. After this limit is reached, abnormal grain growth can occur.

At $400{ }^{\circ} \mathrm{C}$, the experimentally observed grain size is initially much less than that of $\mathrm{R}_{\mathrm{c}}$, indicating normal grain growth. However, the observed grain sizes are quite close to the critical grain size for longer duration anneals e.g. 64,800 s (1080 min), during which wider normalized grain size distributions were observed, again indicating occurrence of abnormal grain growth (Figure 6). Finally, at $450{ }^{\circ} \mathrm{C}$, a different behavior is observed; the experimental grain size is greater than $R_{c}$. From Figure 6, it can be seen that after the initial decrease (probably due to completion of recrystallization) there is an increase in the width of the distribution after $240 \mathrm{~s}$ (4 min) after which it varies to a lesser degree as compared to other temperatures. Since a few grains grow to a much larger size than the average matrix grain size, the overall mean grain size is larger than the limiting grain size.

It is concluded that the observed mode of grain growth matches up, within the limits of experimental error, with the Zener pinning model. As such, the observed abnormal grain growth 
behavior appears to be more controlled by the evolution in second phase particle microstructure than it is by the presence of an initial crystallographic texture. However, the possibility that the initial texture and grain boundary anisotropy contribute to some degree is not entirely ruled out.

\section{3. Mechanism of texture evolution - role of the grain boundary character distribution}

For all the temperatures investigated, the basal texture intensity either remains the same or increases during annealing, as observed previously in the same alloy [52]. Moreover, there is temperature dependence in the behavior. The texture strength remains more or less constant at $300^{\circ} \mathrm{C}$, even for long duration anneals, whereas it strengthens considerably for the $400^{\circ} \mathrm{C}$ and $450^{\circ} \mathrm{C}$ cases. On increasing the annealing temperature, the peak in the texture intensity occurs for a shorter annealing duration. The peak texture intensity is higher in case of 400 than $450{ }^{\circ} \mathrm{C}$. It is known that with increase in temperature, there is a reduction in the number and width of the grain boundary energy cusps in the high angle regime due to entropy effects [53]. Thus, grain boundary energy anisotropy is more prominent at lower temperatures and may be responsible for this observation. If high texture strength is an objective, this finding provides a clue to optimize the strengthening effect of grain growth annealing. That said, the increase of the $\{0001\}\langle 11 \overline{2} 0\rangle$ component over the $\{0001\}<10 \overline{1} 0>$ component as evident in Figure 9 initially occurs more quickly at $450^{\circ} \mathrm{C}$ than at $400^{\circ} \mathrm{C}$. It is noted that these two components are related by a rotation of $30^{\circ}$ about $<0001>$. Thus, it was of interest to study the evolution of these particular components particularly in context of the GBCD.

The driving force for grain growth is reduction in grain boundary energy. A grain will either grow or shrink based on whether its grain boundaries can move easily, which is determined by the grain boundary mobility as well as whether it is energetically advantageous to eliminate that boundary over others. Quite a few simulations studies [54-56] using Monte Carlo 
methods have concluded that anisotropy in grain boundary energy and mobility has a profound effect on the texture evolution during grain growth. For example, studies have reported that in case of a randomly oriented polycrystal, the texture remains random during grain growth and anisotropic grain boundary energy has a greater influence than anisotropic mobility, as seen from the evolution of the GBMD. The frequency of LAGBs increases in case of the anisotropic energy but remains more or less invariant in case of anisotropic mobility [54,55,57]. However, for microstructures with a strong single component texture, both anisotropy in energy and mobility play strong roles. The texture strengthens and the misorientation distribution skews towards the low angle side, indicating an increase in the frequency of low angle boundaries.

Monte Carlo simulations [58] , models based on statistical framework [46,47,59] as well as phase field modeling [60] suggest that if only anisotropic mobilities are considered, the primary component tends to weaken and the weaker one tends to increase in strength (for the case of a two texture component system). If annealing is continued further it can be seen that once the primary texture is replaced by the initially weaker component, then there is another reversal and the initial primary texture begins to strengthen again, leading to an oscillation of the two components. However, if only the grain boundary energy is anisotropic, the primary texture component strengthens monotonically. One common conclusion from all these studies is that anisotropic grain boundary properties can lead not only to strengthening or weakening of the initial texture component, but also an oscillation between components, based on the degree of anisotropy.

It is presently observed that texture intensity becomes stronger during grain growth, irrespective of whether the modes of grain growth are normal or abnormal. The LAGBs occupy a larger fraction as compared to the HAGBs and this fraction increased during annealing. These 
LAGBs are known to have low energy per the Read-Shockley type analysis $[17,61]$. This increase in fraction of LAGBs at the cost of high energy boundaries is due to the reduction in the energy of the system and is in line with the simulations carried out by Dillon and Rohrer [62], which showed that high energy boundaries tend to get consumed at a faster rate than the low energy boundaries. This increase in the fraction of the LAGBs correlates with the observed strengthening of the basal texture. Other grain boundaries, such as $75.06^{\circ}<11 \overline{2} 0>$, tend to persist (Figures $13(\mathrm{a}-\mathrm{d})$ ). It is known from earlier MD simulations results that the special grain boundaries have low energy. Thus, it is not unreasonable to assume that these boundaries, due to their lower energy, remain in the microstructure after longer anneals. Another characteristic feature of this material is the presence of $<0001>30^{\circ}$ boundaries. Earlier studies $[28,63]$ on coincident site lattice (CSL) boundaries in hexagonal materials have identified the "special" $<0001>27.80^{\circ}$ disoriented boundaries as $\Sigma 13$, which possess perfect coincidence independent of the c/a ratio. Such $<0001>\sim 30^{\circ}$ boundaries have been previously identified in hcp materials like $\mathrm{Zn}$ and $\mathrm{Cd}$ [27] and it was found that these originated during the recrystallization in hep metals for e.g. by Gottstein et al. [1] for AZ31 and a Zr-Hf alloy by Zhu et.al [21,64].

As shown in Fig. 12d, in case of longer duration anneal at $450{ }^{\circ} \mathrm{C} 1320 \mathrm{~min}$, the correlated misorientation distribution is very similar to the uncorrelated one. Interestingly, this corresponds to the annealing condition where the misorientation axis distribution for $30^{\circ}$ boundaries changes from [0001] to random. This suggests that these $30^{\circ}$ [0001] grain boundaries are present, with a higher frequency than that simply demanded by the texture. It also highlights the fact that they initially persist with annealing but eventually go away. It is to be noted that their behavior is distinct from the $86^{\circ}<11 \overline{2} 0>$ extension twin boundaries which only show a peak at $86^{\circ}$ only in the correlated misorientation distribution. A recent study [65] has shed some light 
on the origin of these $<0001>30^{\circ}$ boundaries and has discussed the possible mechanism for their formation during continuous dynamic recrystallization. However, there has not been any study yet which explains why it persists in the microstructure during grain growth.

It is found that only after long anneals, we observe the growth of the $\mathrm{R}$ component. As this component increases, the frequency of the $30^{\circ}<0001>$ boundary decreases. For example, upon annealing at a higher temperature of $450^{\circ} \mathrm{C}$ for $79,200 \mathrm{~s}(1320 \mathrm{~min})$, the peak at $30^{\circ}$ persists although in a much lesser fraction, whereas the axis distribution is almost homogeneous. At the same time, the $\{0001\}\langle 11 \overline{2} 0\rangle$ component seems to dominate over $\{0001\}<10 \overline{1} 0>$. Since these two components are related by a rotation of $30^{\circ}$ about $<0001>$, the reduction in the $30^{\circ}<0001>$ boundaries might be a plausible reason for the growth of this particular component, which eventually leads to the mosaic appearance of the (10 $\overline{1} 0)$ pole figure.

\section{Conclusions}

Grain growth annealing in AZ31B alloy has been studied over temperatures ranging from 260 $450{ }^{\circ} \mathrm{C}$ leading to grain sizes ranging from $5-50 \mu \mathrm{m}$.

1) The kinetics of grain growth in this alloy have been established. It is found that the grain growth exponent $\mathrm{n}=5$ and the activation energy $\mathrm{Q}$ is $115 \mathrm{~kJ} / \mathrm{mol}$, which agrees well with previous studies of AZ31.

2) Abnormally large grains have been observed for some annealing conditions at 300-450 ${ }^{\circ} \mathrm{C}$. This lead to a transient broadening of the normalized grain size distribution which upon further annealing tightened up, indicating normal grain growth has resumed.

3) Predictions of the Zener pinning theory qualitatively agree with the observed abnormal grain growth phenomenon. 
4) The basal texture intensity increases with annealing durations for all the temperatures investigated in this study. A $(0001)\langle 11 \overline{2} 0\rangle$ texture component, present in the initial microstructure, grows after prolonged annealing at high temperatures.

5) Anisotropic grain boundary energy and mobility are hypothesized to be responsible for the texture evolution. It is suggested that the low energy and mobility of low angle grain boundaries (LAGB) is the reason for the observed texture strengthening. The fact that LAGB dominate the misorientation distribution after longer duration anneals is supporting evidence.

6) A grain boundary having a $\sim 30^{\circ}$ disorientation about $<0001>$ axes is observed to be present with high frequency in the recrystallized microstructure and tend to persist during grain growth annealing.

\section{Acknowledgements}

This work was financially supported by Research at Oak Ridge National Laboratory, managed by UT Battelle, LLC, for the U.S. Department of Energy (DOE) under contract DE-AC0500OR22725, sponsored by the Office of Energy Efficiency and Renewable Energy for the Vehicle Technologies and by the National Science Foundation, grant number CMMI 1235259. The authors are grateful for the help of N.T. Nuhfer, S. Bhattacharya and M. Jafari in providing access to the EBSD facilities at Carnegie Mellon University when our SEM was being replaced. H. El Kadiri and C.D. Barrett at Mississippi State University and M.A. Steiner are gratefully acknowledged for fruitful discussions.

\section{References}

[1] Gottstein G, Al Samman T. Mater Sci Forum 2005;495-497:623.

[2] Park YB, Lee DN, Gottstein G. Acta Mater 1998;46:3371.

[3] Lorimer GW, Mackenzie LWF, Humphreys FJ, Wilks T. Mater Sci Forum 2005;488489:99.

[4] Pérez-Prado MT, Ruano OA. Scr Mater 2002;46:149.

[5] Muralidharan G, Muth TR, Peter WH, Watkins TR, Wang Y, Randman D, Davis B, Alderman M, Romanoski C, Hunter F. Shear Rolling of Magnesium Sheet for Automotive , Defense, and Energy Applications.

URL: http://www.osti.gov/scitech/servlets/purl/1098176.

[6] Stand ASTM "E112-96" Stand test methods Determ Aver grain size 2004. 
[7] Anderson MP, Grest GS, Srolovitz DJ. Scr Metall 1985;19:225.

[8] Srolovitz DJ, Grest GH, Anderson MP. Acta Metall 1985;33:2233.

[9] Bruno JC, Rios PR. Scr Metall Mater 1995;32:601.

[10] Dreyer C, Polesak F, Shultz T, Agnew S. Blind Study of the Effect of Processing History on the Constitutive Behaviour of Alloy AZ31B., in.. Proc. 138th TMS Annu. Meet. Exhib. San Fransisco, CA. 2009.

[11] Stock SR, Cullity BD. Elements of X-Ray Diffraction, third edit. Prentice Hall, Upper Saddle River, NJ; 2001.

[12] Engler O, Randle V. Introduction to Texture Analysis: Macrotexture, Microtexture, and Orientation Mapping. 2009.

[13] Underwood E. Quantitative Stereology. 1970.

[14] Srolovitz DJ, Anderson MP, Grest GH, Sahni PS. Acta Metall 1984;32:1429.

[15] Grest GS, Srolovitz DJ, Anderson MP. Acta Metall 1985;33:509.

[16] Hillert M. Acta Metall 1965;13:227.

[17] Humphreys FJ, Hatherly M. Recrystallization and Related Annealing Phenomena. Elsevier; 2004.

[18] Abbruzzese G. Acta Metall 1985;33:1329.

[19] Frost H. J, Thompson CV, Walton DT. Acta Metall Mater 1992;40:779.

[20] Agnew SR. Plastic Anisotropy of Magnesium Alloy AZ31B Sheet., in:. Kaplan HI (Ed.). Magnes. Technol. 2002. TMS (The Minerals, Metals \& Materials Society), 2002; 2002.

[21] Zhu KY, Bacroix B, Chauveau T, Chaubet D, Castelnau O. Metall Mater Trans A 2009;40:2423.

[22] Yamamoto A, Kakishiro M, Ikeda M, Tsubakino H. Mater Sci Forum 2004;449-452:669.

[23] Stanford N, Atwell D. Metall Mater Trans A 2013;44:4830.

[24] Ren YP, Qin GW, Pei WL, Zhao HD, Guo Y, Li HX, Jiang M, Hao SM. J Alloys Compd 2009;479:237.

[25] Wang J, Beyerlein IJ. Model Simul Mater Sci Eng 2012;20:024002.

[26] Wang J, Beyerlein IJ. Metall Mater Trans A 2012;43:3556.

[27] Klar R, Lucke K. Z Met 1968;59:194.

[28] Warrington DH. Le J Phys Colloq 1975;36:87.

[29] Burke JE, Turnbull D. Prog Met Phys 1952;3:220.

[30] Su CW, Lu L, Lai MO. Philos Mag 2008;88:181.

[31] Miao Q, Hu L, Wang X, Wang E. J Alloys Compd 2010;493:87.

[32] Wang X, Hu L, Liu K, Zhang Y. J Alloys Compd 2012;527:193.

[33] Frost H, Ashby M. Deformation Mechanism Maps: The Plasticity and Creep of Metals and Ceramics. Pergamon Press; 1982.

[34] Yu CY, Sun PL, Kao PW, Chang CP. Mater Sci Eng A 2004;366:310.

[35] Miao Q, Hu L, Wang X, Wang E. J Alloys Compd 2010;493:87.

[36] Gottstein G, Shvindlerman LS. Grain Boundary Migration in Metals: Thermodynamics, Kinetics, Applications. CRC Press; 1999.

[37] Feltham P. Acta Metall 1957;5:97.

[38] Yamakov V, Moldovan D, Rastogi K, Wolf D. Acta Mater 2006;54:4053.

[39] Das SK, Kim Y-M, Ha TK, Gauvin R, Jung I-H. Metall Mater Trans A 2013;44:2539.

[40] Rollett AD, Srolovitz DJ, Anderson MP. Acta Metall 1989;37:1227. 
[41] Nadella RK, Samajdar I, Gottstein G. Static Recrystallization and Textural Changes in Warm Rolled Pure Magnesium, in:. Magnes. Proc. 6th Int. Conf. Magnes. Alloy. Their Appl. Wiley - VCH Verlag GmbH Co. KGaA, 2005. 2003.

[42] Thompson CV, Frost HJ, Spaepen F. Acta Metall 1987;35:887.

[43] Beck PA, Sperry PR. Trans AIME 1949;185:240.

[44] Dahms M, Welch PI, Bunge HJ. Scr Metall 1982;16:827.

[45] Distl JS, Welch PI, Bunge HJ. Scr Metall 1983;17:975.

[46] Abbruzzese G, Lücke. K. Acta Metall 1986;34:905.

[47] Eichelkraut H, Abbruzzese G, Lücke K. Acta Metall 1988;36:55.

[48] Omura T, Hayakawa Y. Mater Trans 2013;54:14.

[49] Hayakawa Y, Szpunar JA. Acta Metall 1997;45:4713.

[50] Manohar PA, Ferry M, Chandra T. ISIJ Int 1998;38:913.

[51] Vander Voort GF. Metallography, Principles and Practice. ASM International; 1984.

[52] Yang X, Miura H, Sakai T. Mater Trans 2005;46:2981.

[53] Erb U, Gleiter H. Scr Metall 1979;13:61.

[54] Holm EA, Hassold GN, Miodownik MA. Acta Mater 2001;49:2981.

[55] Miodownik M, Godfrey A, Holm E, Hughes D. Acta Mater 1999;47:2661.

[56] Rollett AD. Mater Sci Forum 2002;408-412:251.

[57] Upmanyu M, Kazaryan A, Holm EA, Wang Y, Patton B. Interface Sci 2002;10:201.

[58] Mehnert K, Klimanek P. Scr Mater 1996;35:699.

[59] Lücke K., Brandt R, Mariani. G. Mater Sci forum 1998;273:41.

[60] Ma N, Kazaryan A, Dregia S, Wang Y. Acta Mater 2004;52:3869.

[61] Read WT, Shockley. W. Phys Rev 1950;78.

[62] Dillon SJ, Rohrer GS. Acta Mater 2009;57:1.

[63] Bonnet R, Cousineau E, D.H.Warrington. Acta Crystallogr Sect A Cryst Physics, Diffraction, Theor Gen Crystallogr 1981;37:184.

[64] Zhu KY, Chaubet D, Bacroix B, Brisset F. Acta Mater 2005;53:5131.

[65] Molodov KD, Al-Samman T, Molodov D a., Gottstein G. Acta Mater 2014;76:314. 

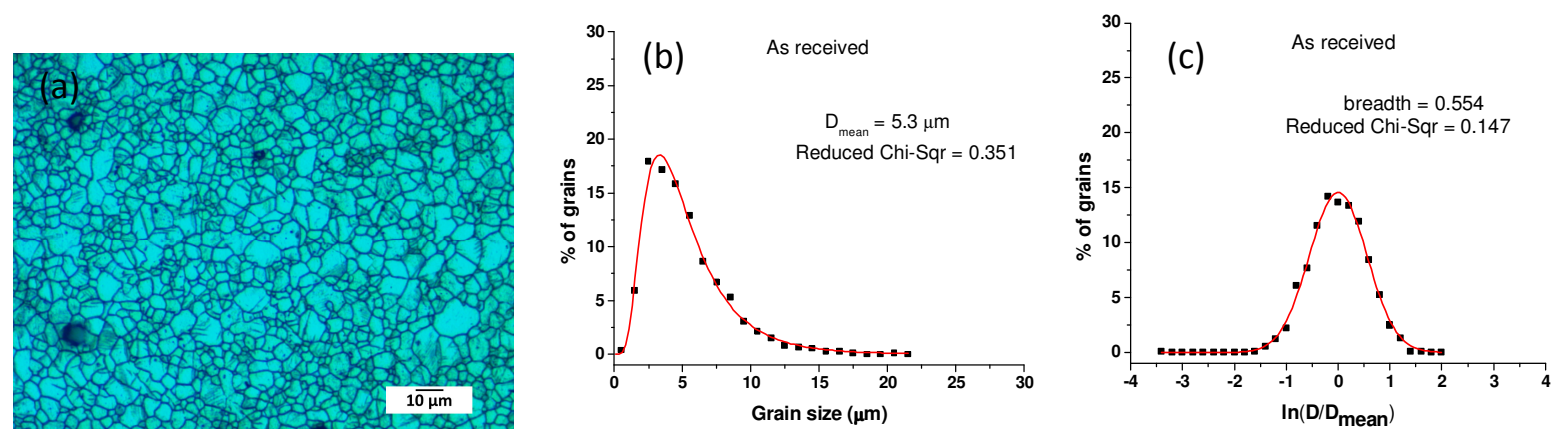

(d)
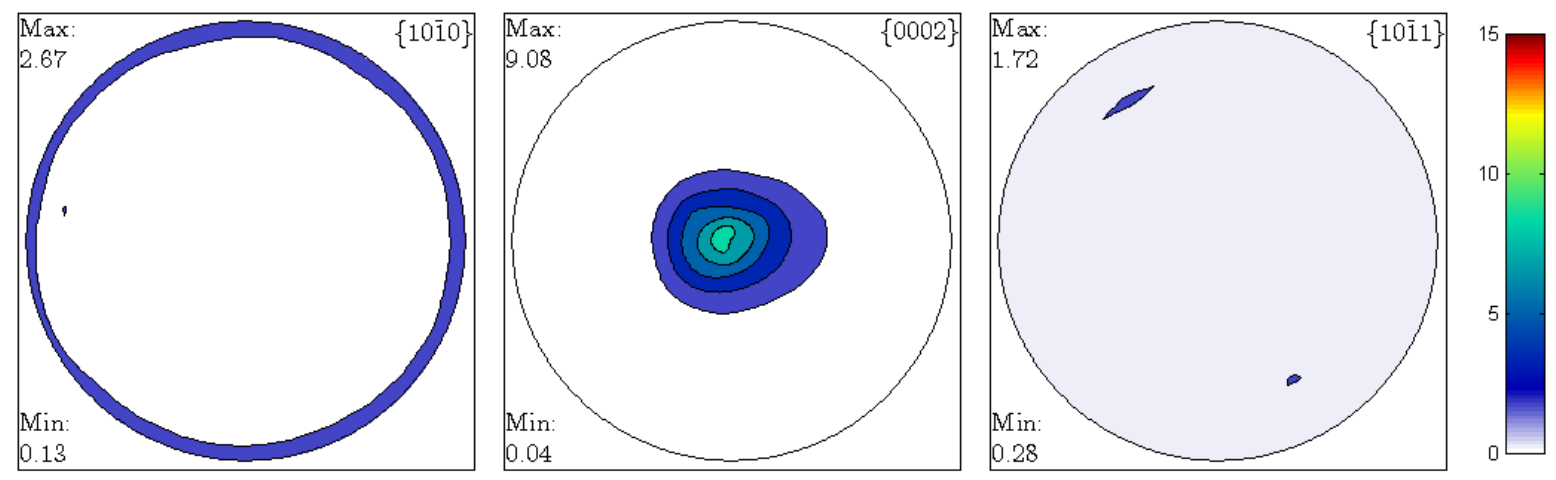

Figure 1: Microstructure and texture of as rolled AZ31 sheet. (a) Optical micrograph illustrating the fine, equiaxed initial grain morphology in the as received condition. (b) The grain size distribution along with the fit with log normal distribution (c) distribution normalized by the mean grain size showing the breadth of the normalized distribution. The reduced chi square values as obtained from the fits are also shown. (d) Recalculated full pole figures from the midplane, with the rolling direction horizontal, the transverse direction vertical and the normal direction out of the page. 

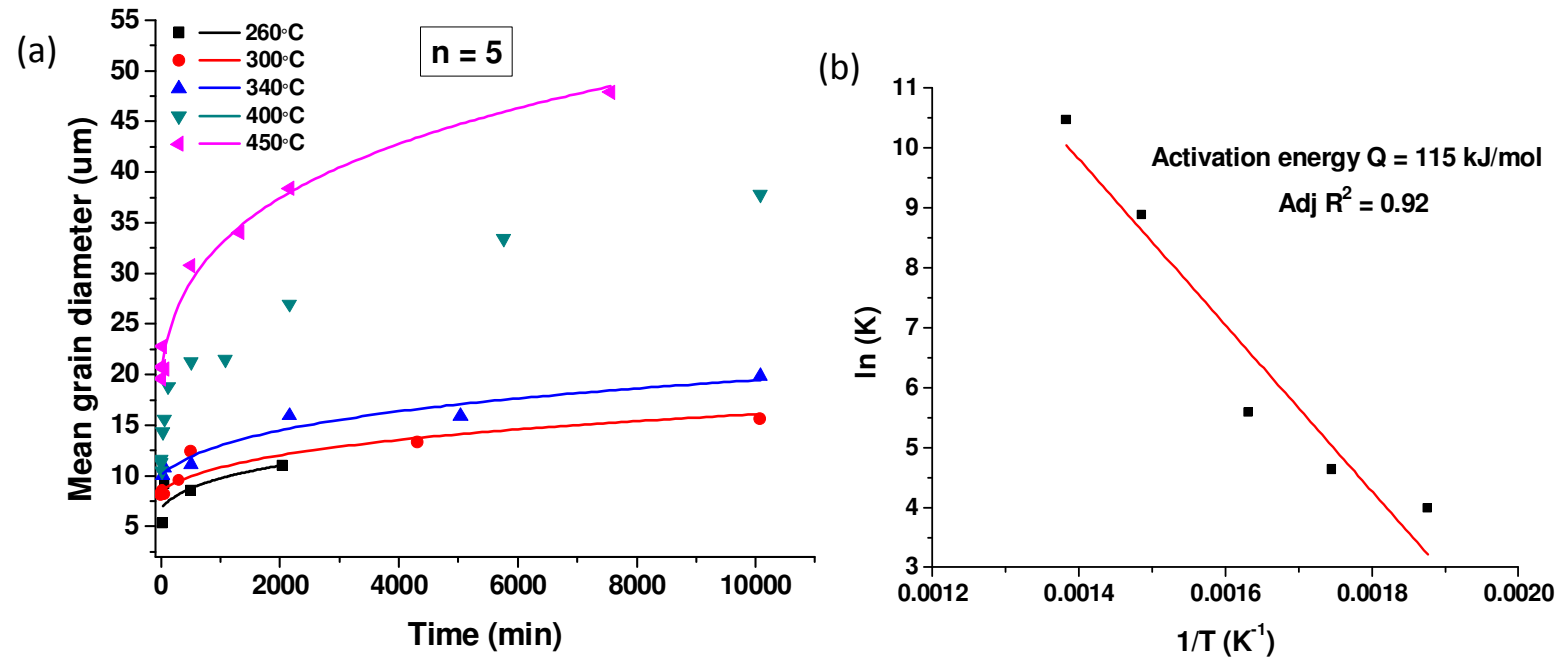

Figure 2: (a) - The variation of mean grain diameter with annealing time along with the fit with Equation 1, for all the temperatures investigated in this study. (b) - The plot of natural logarithm of $k$ vs. $1 / T$ along with the linear fit, showing the activation energy $Q=115 \mathrm{~kJ} / \mathrm{mol}$.
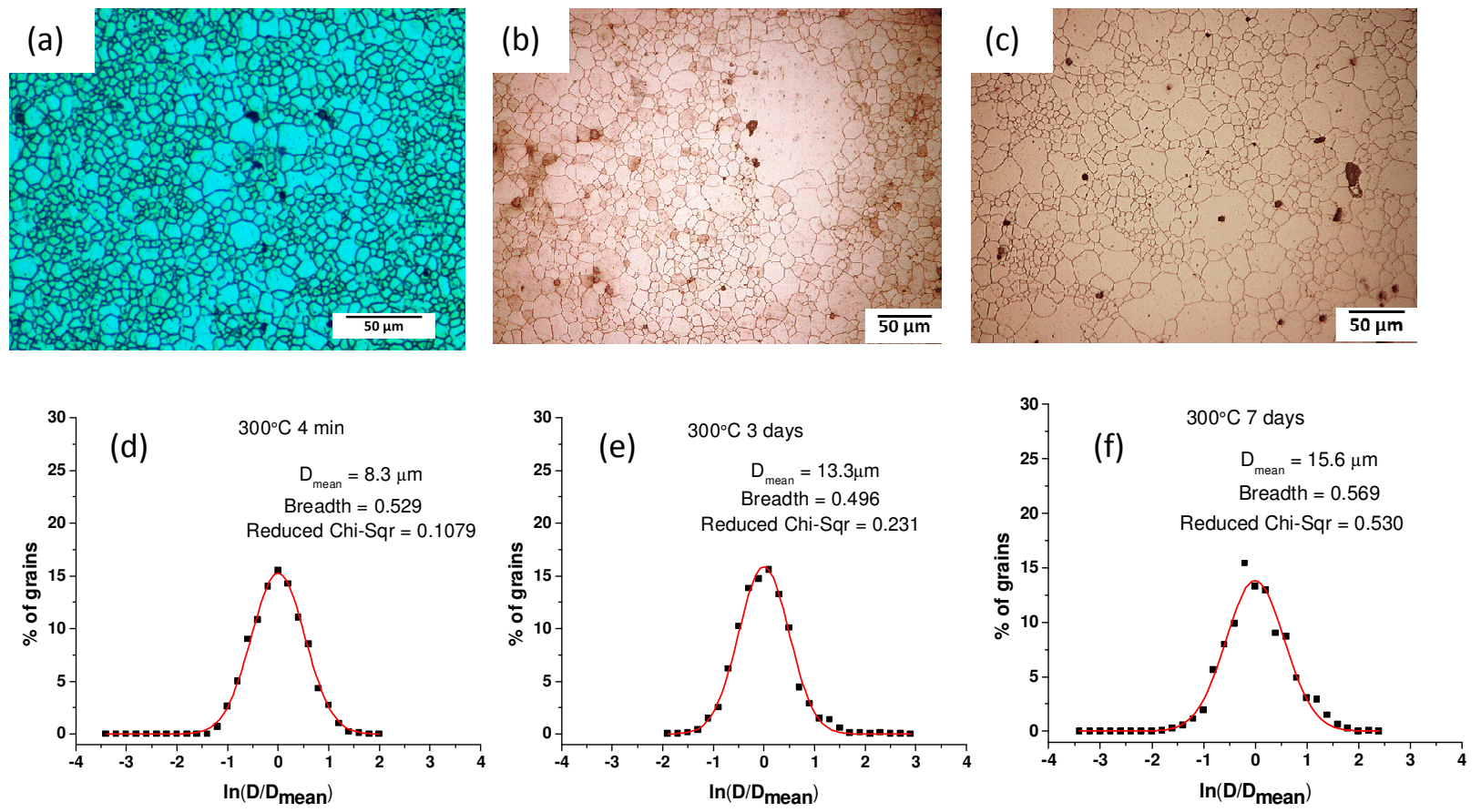

Figure 3: Optical micrographs for annealing conditions of (a) $300{ }^{\circ} \mathrm{C} 60 \mathrm{~s}(1 \mathrm{~min})$ (b) $300{ }^{\circ} \mathrm{C}$ 259,200 s (3 days) and (c) $300{ }^{\circ} \mathrm{C} 604,800 \mathrm{~s}$ (7 days). The corresponding normalized grain size distributions are shown in $(d),(e)$ and $(f)$ respectively. 

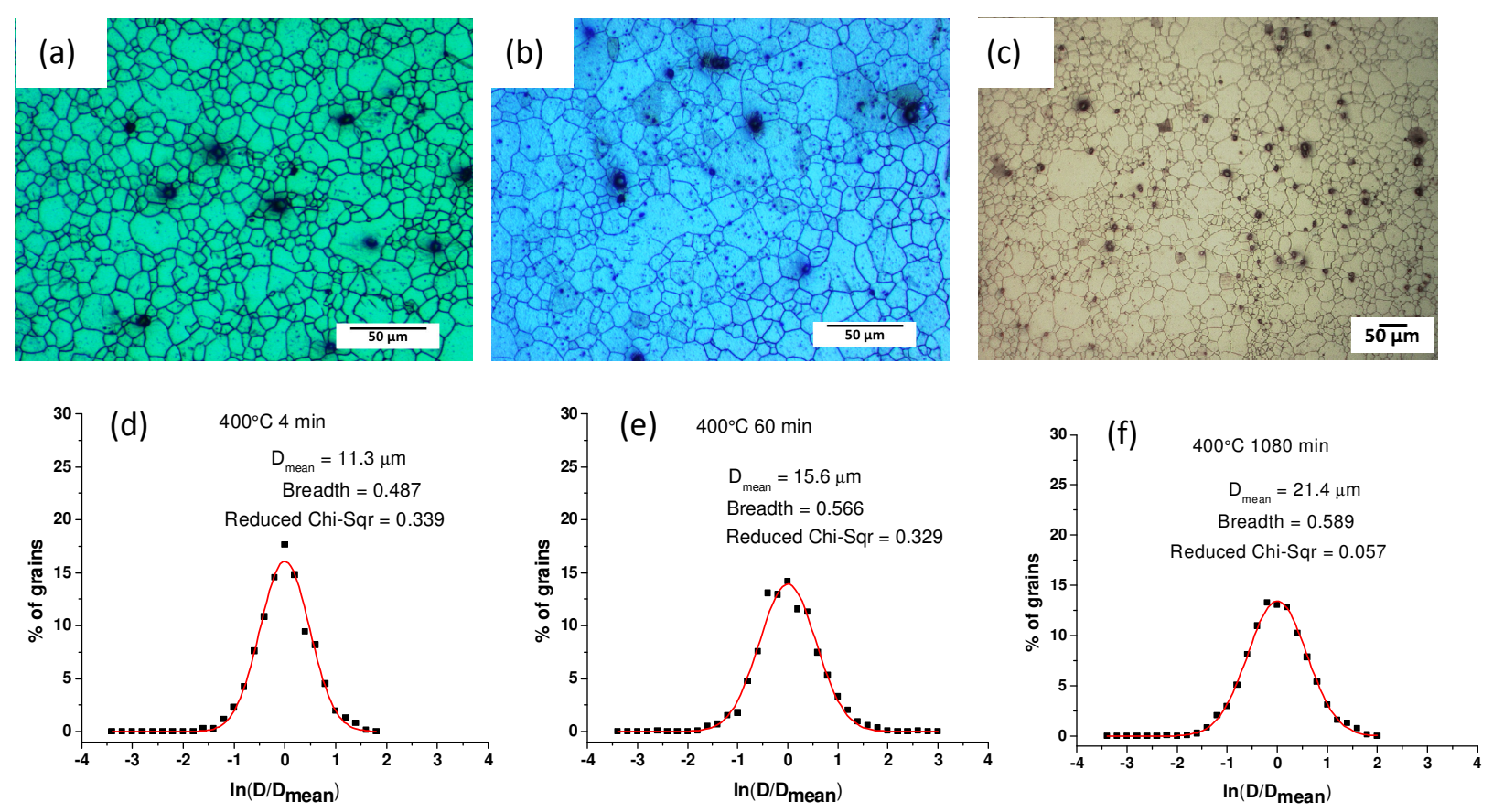

Figure 4: Optical micrographs for annealing conditions of (a) $400{ }^{\circ} \mathrm{C} 60 \mathrm{~s}(1 \mathrm{~min})(\mathrm{c}) 400{ }^{\circ} \mathrm{C}$ $3600 \mathrm{~s}$ (60 min) and (e) $400{ }^{\circ} \mathrm{C} 64,800 \mathrm{~s}$ (1080 min). The corresponding normalized grain size distributions are shown in $(d),(e)$ and $(f)$ respectively.
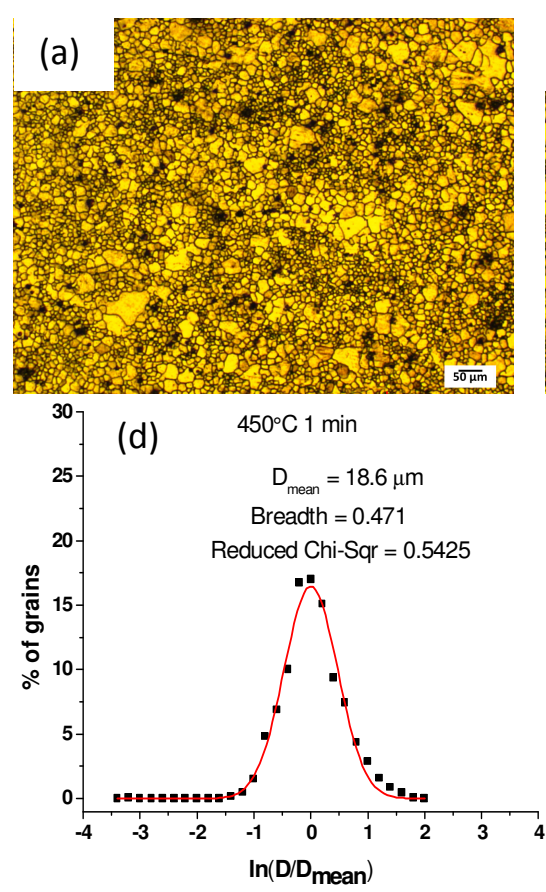
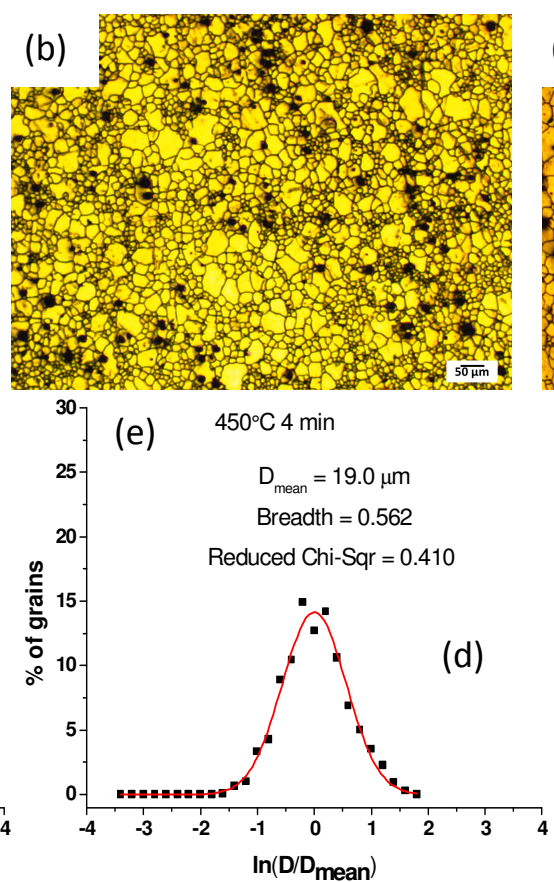
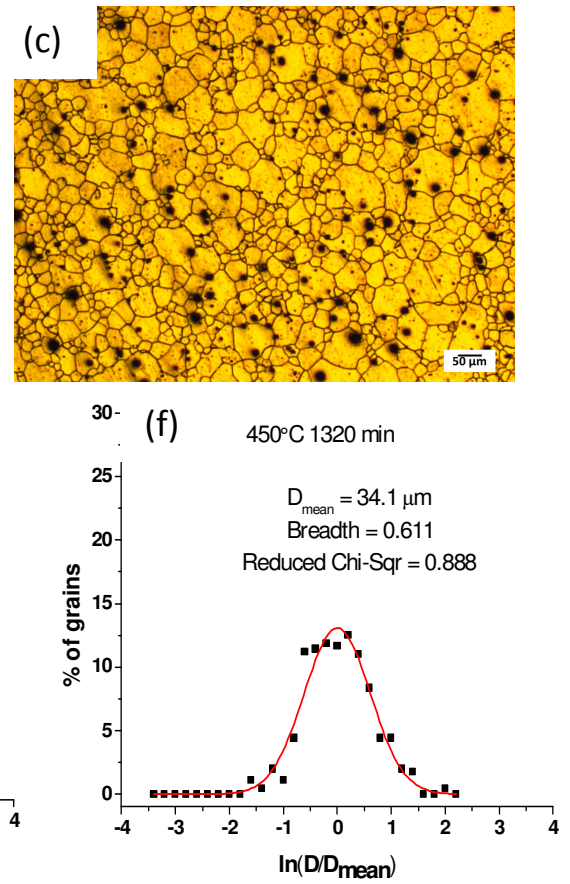

Figure 5: Optical micrographs for annealing conditions of (a) $450{ }^{\circ} \mathrm{C} 60 \mathrm{~s}(1 \mathrm{~min})(\mathrm{c}) 450^{\circ} \mathrm{C}$ $240 \mathrm{~s}$ (4 min) and $(e) 450^{\circ} \mathrm{C} 79,200 \mathrm{~s}$ (1320 min). The corresponding normalized grain size distributions are shown in $(d),(e)$ and $(f)$ respectively. 


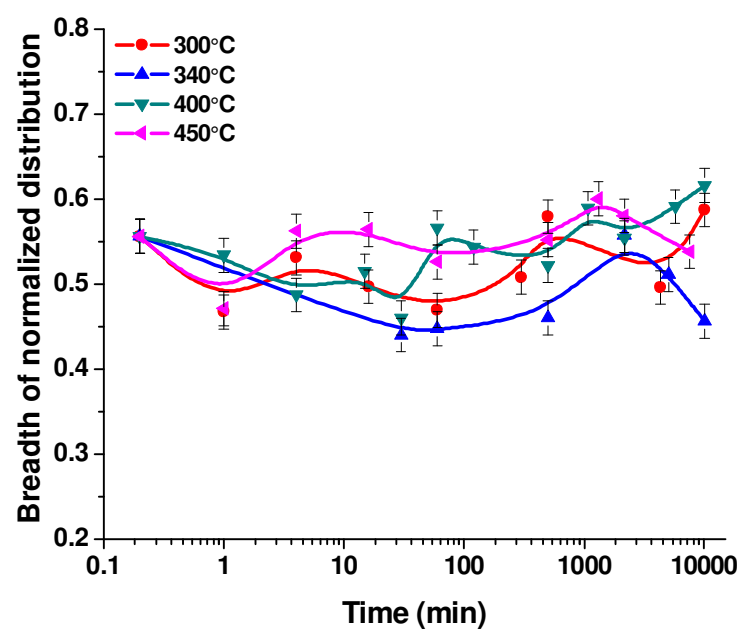

Figure 6: Variation of the width of the normalized distribution a function of annealing time for annealing at $300^{\circ} \mathrm{C}, 340^{\circ} \mathrm{C} 400^{\circ} \mathrm{C}$ and $450^{\circ} \mathrm{C}$. Curves serve to guide the eye.

(a)

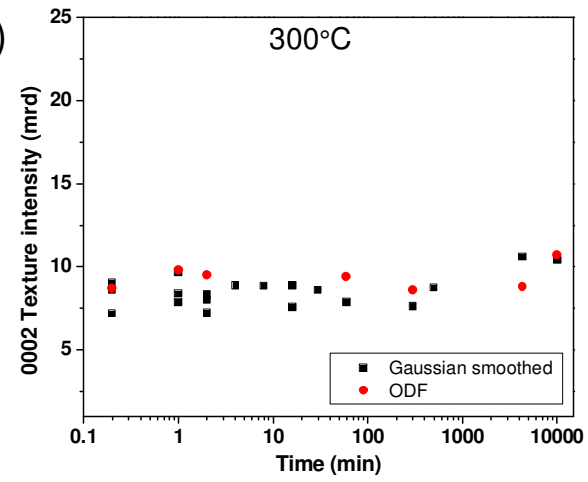

(c)

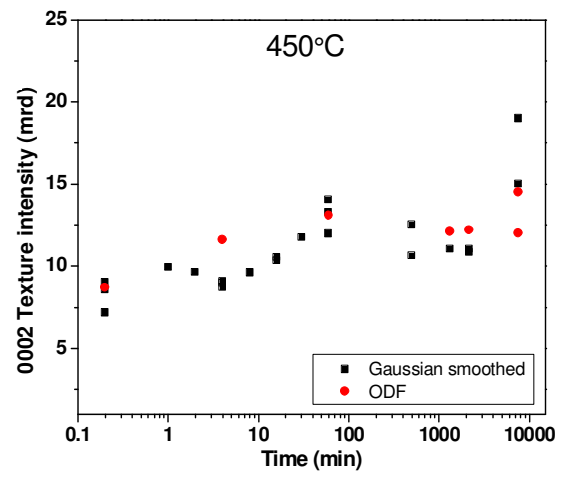

(b)

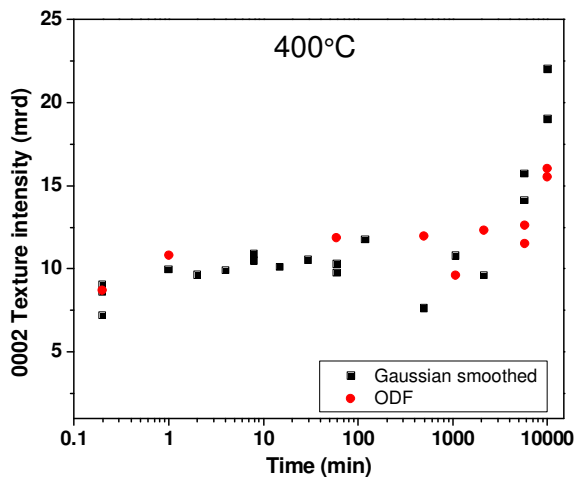

(d)

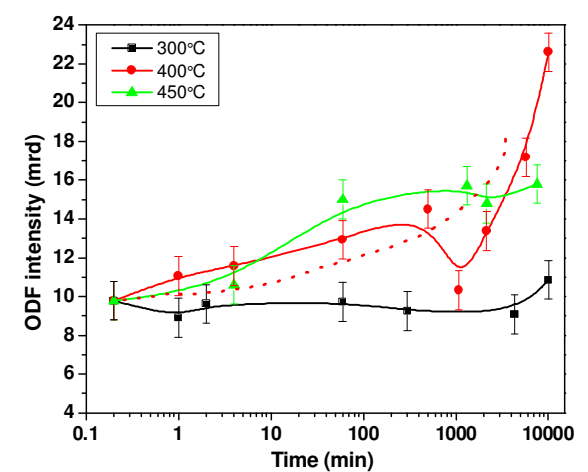

Figure 7: Peak intensity of the (0002) pole figures plotted as a function of annealing time at three different temperatures a) $300, b) 400$, c) $450^{\circ} \mathrm{C}$, and d) evolution of the maximum ODF intensity. Curves serve to guide the eye. 

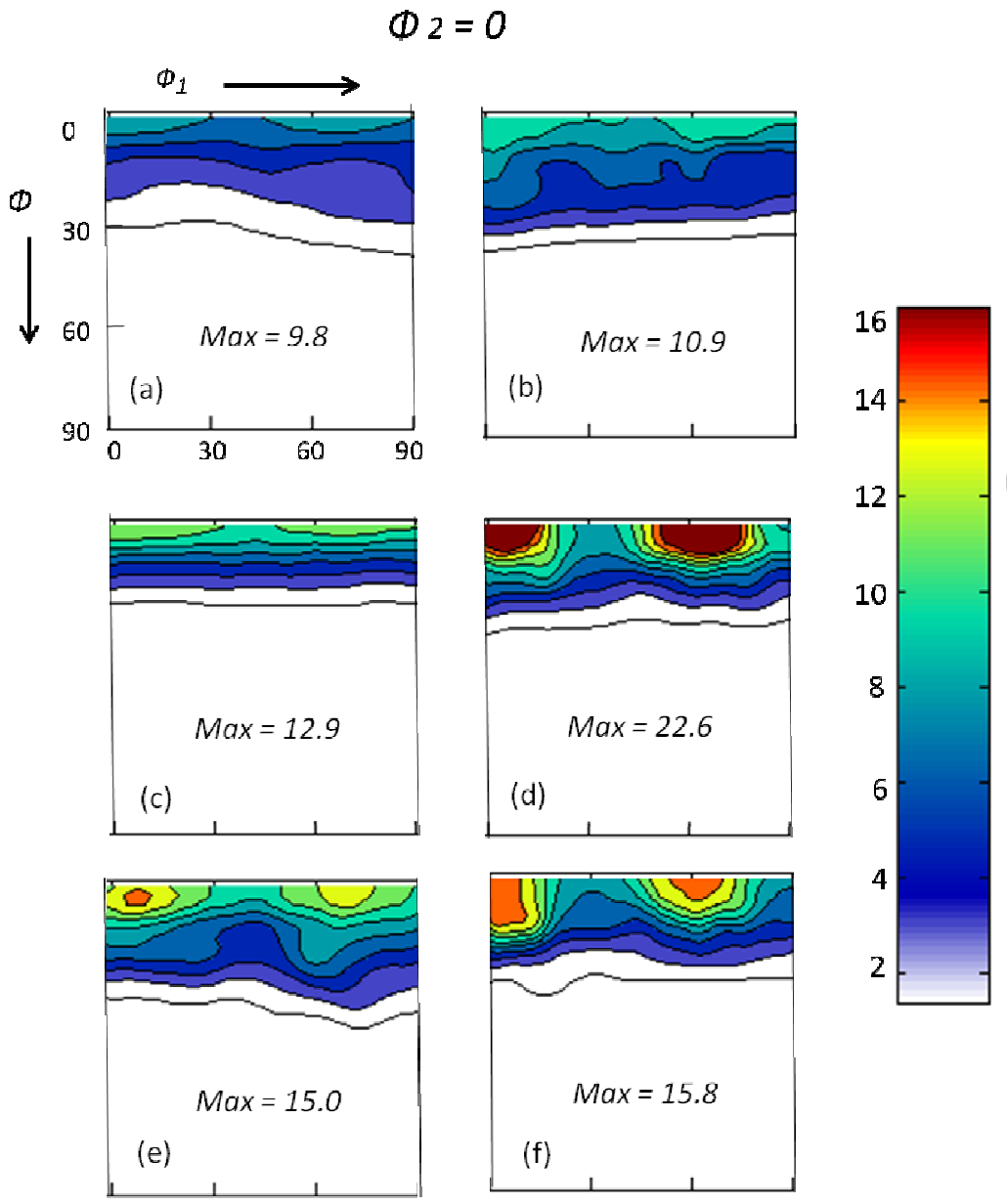

Figure 8: ODF sections phi $2=0$ for (a) the as received sheet and samples annealed at (b) 300 ${ }^{\circ} \mathrm{C} 604,800 \mathrm{~s}$ ( 7 days) (c) $400{ }^{\circ} \mathrm{C} 3600 \mathrm{~s}(60 \mathrm{~min})(\mathrm{d}) 400{ }^{\circ} \mathrm{C} 604,800 \mathrm{~s}\left(7\right.$ days) (e) $450{ }^{\circ} \mathrm{C} 3600$ $s(60 \mathrm{~min})$ and $(f) 450^{\circ} \mathrm{C} 453,600 \mathrm{~s}$ (5.25 days).
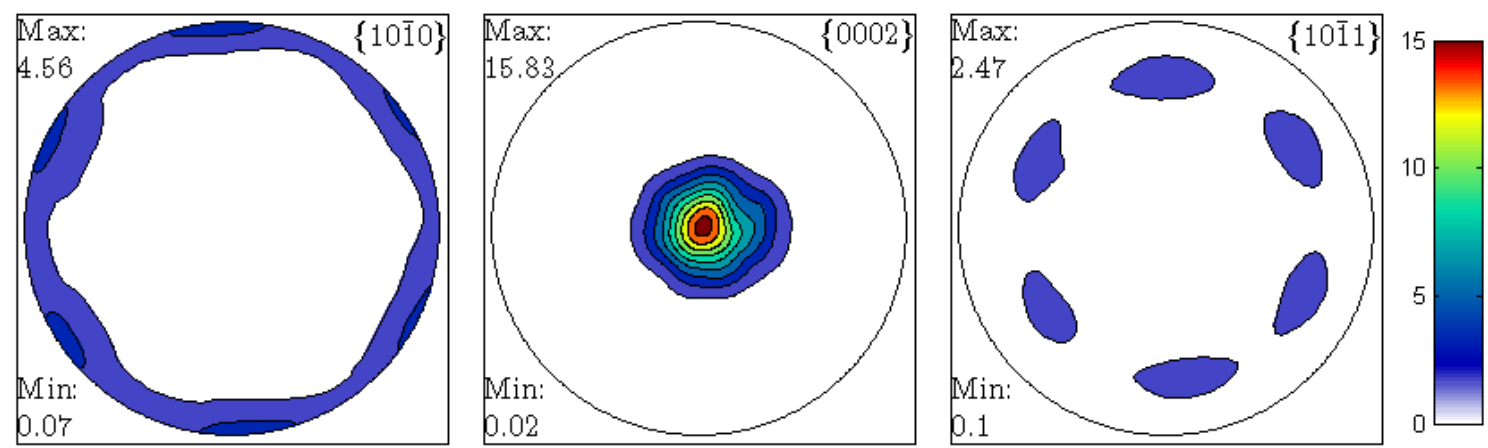

Figure 9: Recalculated full pole figures after a long duration anneal of 604,800 s (7 days) at 400 ${ }^{\circ} \mathrm{C}$ showing the single orientation, (0001) $\langle 11 \overline{2} 0\rangle$, which develops. (Rolling direction horizontal, transverse direction vertical and the normal direction out of the page.) 

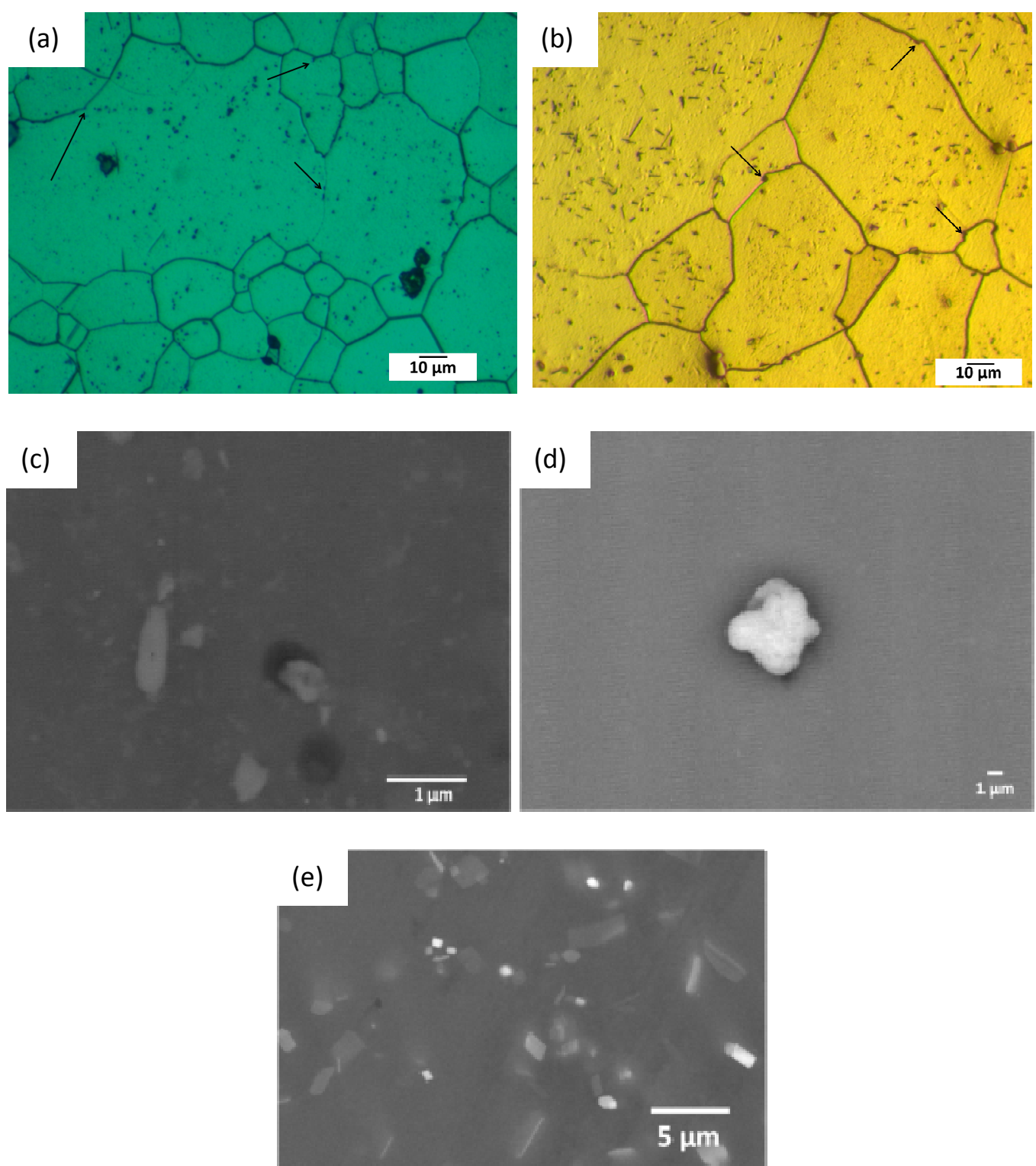

Figure 10: Optical micrograph of a sample annealed at (a) $450{ }^{\circ} \mathrm{C} 3600 \mathrm{~s}(60 \mathrm{~min})$ and (b) 450 ${ }^{\circ} \mathrm{C} 453,600$ s (5.25 days). The black arrows show regions where particles strongly interact with the grain boundaries. Backscattered electron images of samples annealed at various conditions. (c) Impurity based second phase particles in a sample annealed at $300{ }^{\circ} \mathrm{C} 18,000 \mathrm{~s}(300 \mathrm{~min})$ as revealed by EDS. (d) An Al-Mn particle in a sample annealed at $300^{\circ} \mathrm{C} \mathrm{for} 240 \mathrm{~s}$ (4 min). (e) Backscattered electron image of a sample annealed at $450^{\circ} \mathrm{C}$ for $453,600 \mathrm{~s}$ (5.25 days) showing rod and plate shaped second phase particles. 

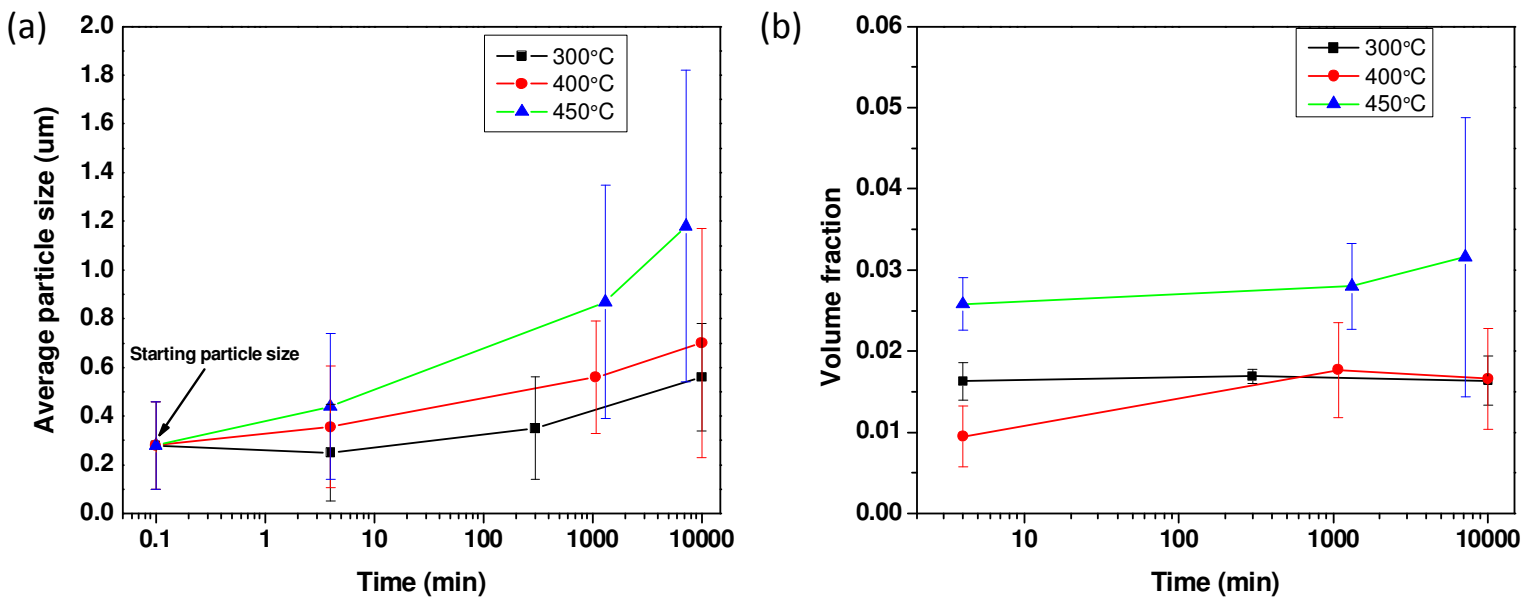

Figure 11: (a) Evolution of particle size with annealing time, showing significant coarsening with annealing time for higher temperatures. (b) Evolution of volume fraction with annealing time showing that it remains relatively constant within the limits of experimental uncertainty. Lines serve to guide the eye. 
(a)

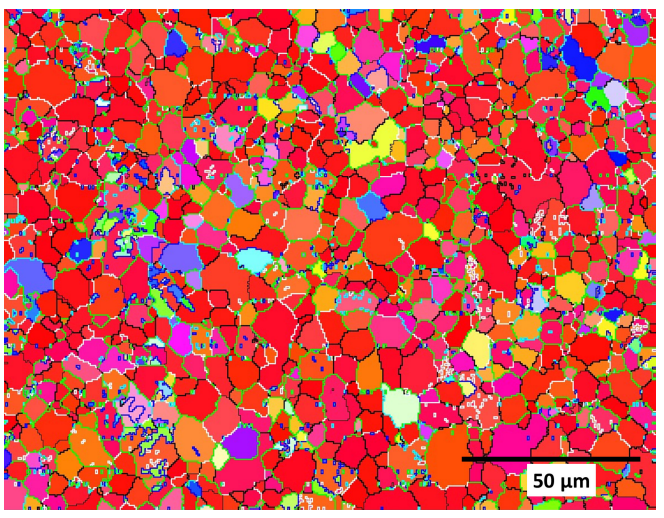

(c)

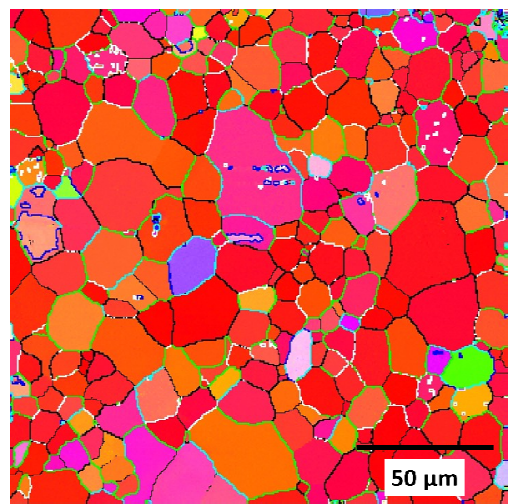

(e)

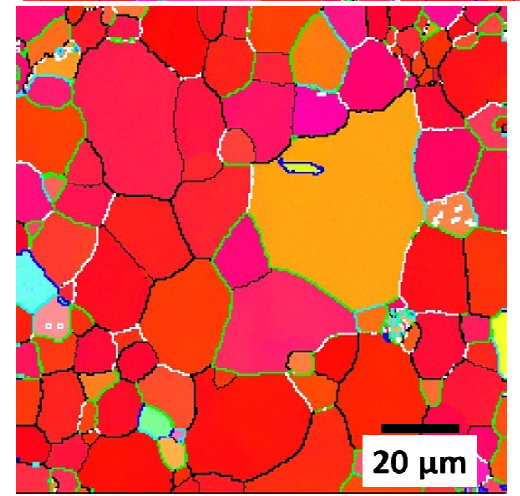

(g)

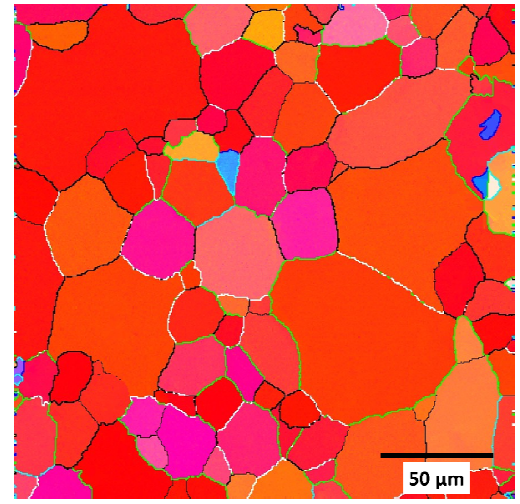

(b)

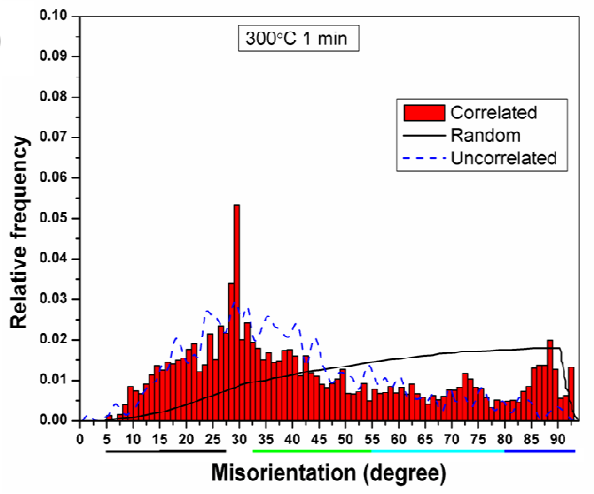

(d)

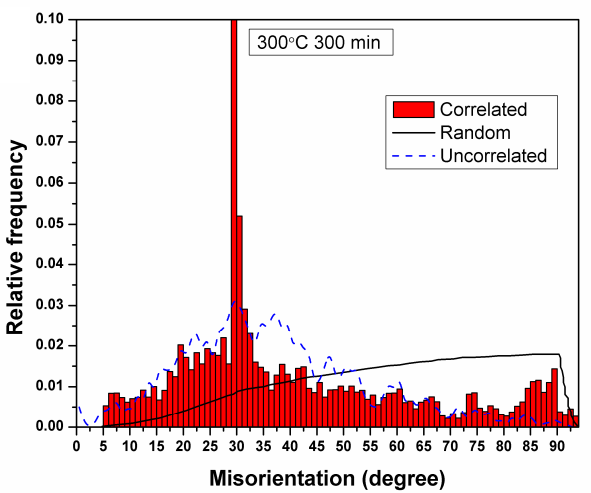

(f)

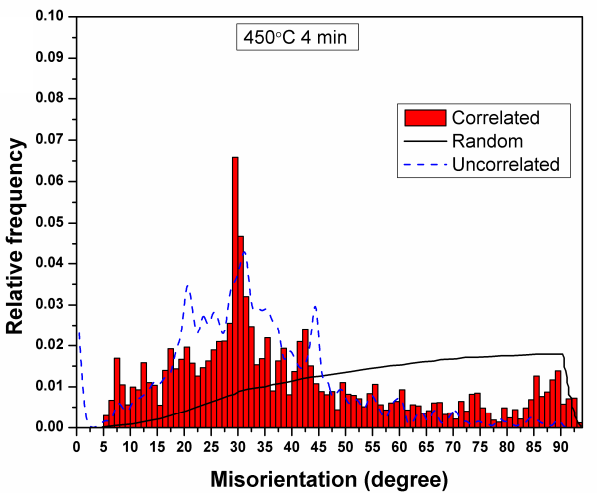

(h)

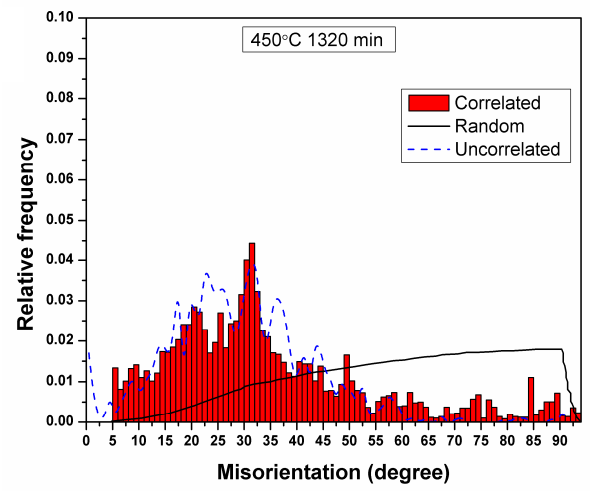

Figure 12a) Inverse pole figure map and $b$ ) the corresponding disorientation distribution for the sample annealed at $300{ }^{\circ} \mathrm{C}$ for $60 \mathrm{~s}(1 \mathrm{~min}) \mathrm{c}$ ) and d) $300{ }^{\circ} \mathrm{C}$ for $18,000 \mathrm{~s}(300 \mathrm{~min}) \mathrm{e}$ ) and f) 450 ${ }^{\circ} \mathrm{C}$ for $240 \mathrm{~s}(4 \mathrm{~min}) \mathrm{g}$ ) and $\left.\mathrm{h}\right) 450{ }^{\circ} \mathrm{C}$ for $79,200 \mathrm{~s}$ (1320 min). 
(a)
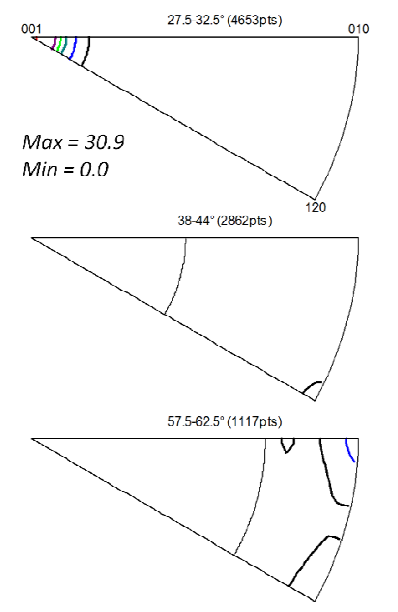

$72-70^{\circ}(1183 \mathrm{pts})$

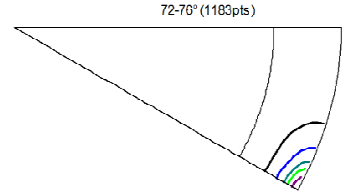

$84-88^{\circ}(1381 \mathrm{pts})$

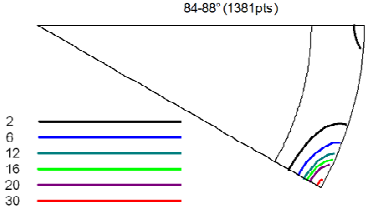

(b)
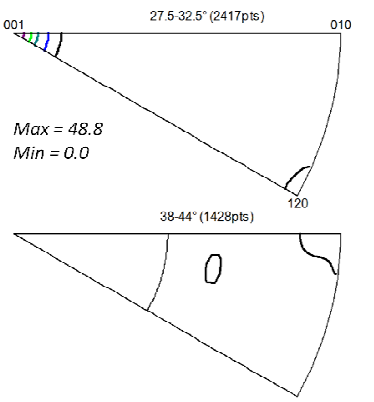

$5 / .562 .5^{\prime}(65 \mathrm{spts})$

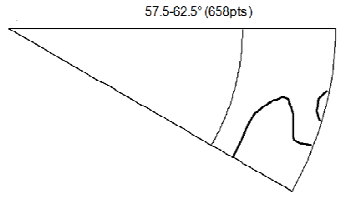

$72-76^{\circ}(121 \mathrm{pts})$

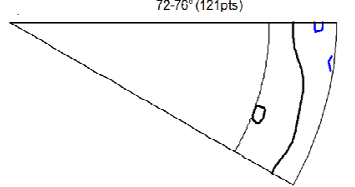

$84-88^{\circ}(4.5 \mathrm{pts})$

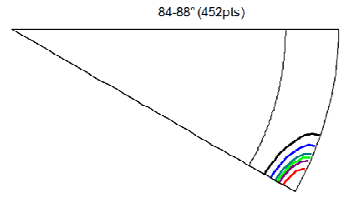

(c)

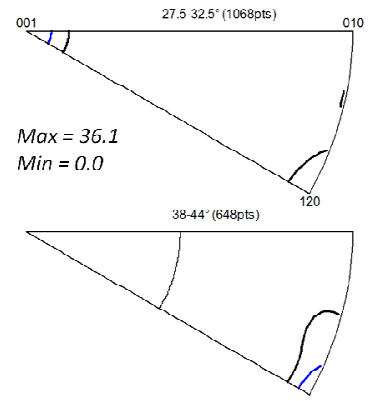

$57.5-62.5^{*}(153 \mathrm{pts})$

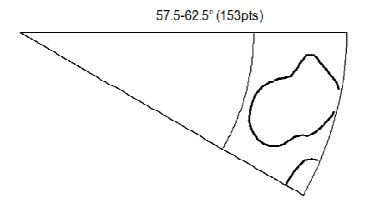

$72-70^{\circ}(41 p t 5)$

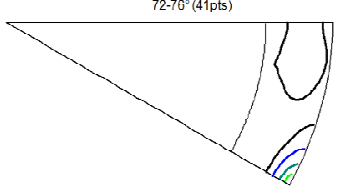

$84-88^{3}(101 \mathrm{pts})$

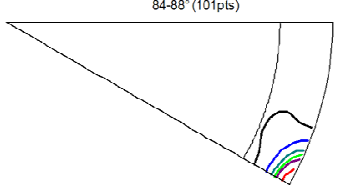

(d)

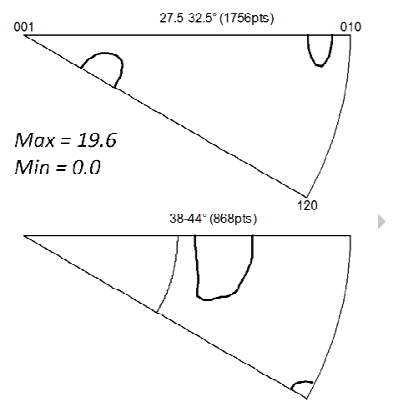

$57.56-62.5^{\prime \prime}(218 \mathrm{pts})$

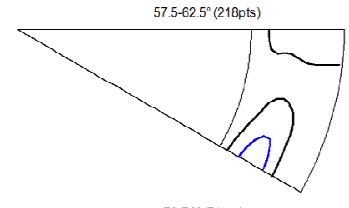

$72-70^{\circ}(71 \mathrm{pts})$

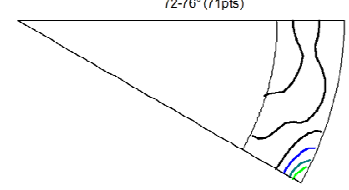

$84-88^{\circ}$ (170pts)

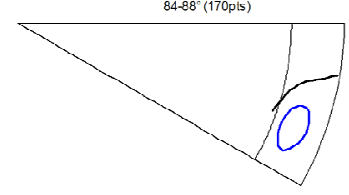

Figure 13: Grain boundary misorientation axes distribution plots for all the disorientation angles presented in Table 1 for a sample annealed at (a) $300{ }^{\circ} \mathrm{C} 60 \mathrm{~s}$ (1 min) (b) $300{ }^{\circ} \mathrm{C} 18,000 \mathrm{~s}$ (300 min) (c) $450{ }^{\circ} \mathrm{C} 240 \mathrm{~s}(4 \mathrm{~min})(\mathrm{d}) 450{ }^{\circ} \mathrm{C} 79,200 \mathrm{~s}$ (1320 min). 
Table 1: The values of initial fitting parameters $n, k, D_{0}$ and the goodness of fit values.

\begin{tabular}{|c|c|c|c|c|}
\hline $\mathrm{T}\left({ }^{\circ} \mathrm{C}\right)$ & $\mathrm{n}$ & $\mathrm{k}$ & $\mathrm{D}_{0}(\mu \mathrm{m})$ & Reduced Chi-sqr \\
\hline 260 & - & - & - & - \\
\hline 300 & $5.7 \pm 0.69$ & $611.1 \pm 1128.6$ & $8.22 \pm 0.14$ & 0.06 \\
\hline 340 & $4.99 \pm 1.89$ & $263.6 \pm 1426.3$ & $10.1 \pm 0.93$ & 1.28 \\
\hline 400 & $5.33 \pm 0.54$ & $21790.6 \pm 39494.8$ & $11.1 \pm 1.19$ & 2.61 \\
\hline 450 & $5.32 \pm 0.63$ & $116170.9 \pm 271480.9$ & $20.3 \pm 0.87$ & 2.04 \\
\hline
\end{tabular}

Table 2: The values of fitting parameters $D_{0}$ and $k$ for $n=5$, and the goodness of fit values.

\begin{tabular}{|c|c|c|c|}
\hline $\mathrm{T}\left({ }^{\circ} \mathrm{C}\right)$ & $\mathrm{k}$ & $\mathrm{D}_{0}(\mu \mathrm{m})$ & Reduced Chi-sqr \\
\hline 260 & $53.6 \pm 26.9$ & $8.2 \pm 0.61$ & 0.71 \\
\hline 300 & $89.8 \pm 5.8$ & $8.3 \pm 0.12$ & 0.06 \\
\hline 340 & $268.0 \pm 48.3$ & $10.1 \pm 0.72$ & 0.96 \\
\hline 400 & $7196.5 \pm 848.1$ & $11.4 \pm 0.95$ & 2.41 \\
\hline 450 & $34981.3 \pm 3285.5$ & $20.4 \pm 0.75$ & 1.81 \\
\hline
\end{tabular}

Table 3 Summary of special grain boundaries in hexagonal metals after [25-28]

\begin{tabular}{|l|l|}
\hline Axis & Angle $^{\left({ }^{\circ}\right.}$ \\
\hline$[1 \overline{2} 10]$ & 31.99 \\
\hline$[1 \overline{2} 10]$ & 43.11 \\
\hline$[1 \overline{2} 10]$ & 61.91 \\
\hline$[1 \overline{2} 10]$ & 75.06 \\
\hline$[01 \overline{1} 0]$ & 28.41 \\
\hline$[01 \overline{1} 0]$ & 39.06 \\
\hline$[01 \overline{1} 0]$ & 58.36 \\
\hline$[01 \overline{1} 0]$ & 72.88 \\
\hline$[0001]$ & 27.80 \\
\hline
\end{tabular}


Table 4: A summary of the results obtained from the calculations using the Zener model.

\begin{tabular}{|c|c|c|c|c|c|c|}
\hline $\begin{array}{l}\text { Temp } \\
\left({ }^{\circ} \mathrm{C}\right)\end{array}$ & Time (s) & $\begin{array}{l}\text { Particle size } \\
(\mu \mathrm{m})\end{array}$ & $\begin{array}{l}\text { Particle volume } \\
\text { fraction }\end{array}$ & $\begin{array}{c}2 \mathrm{D} \text { mean } \\
\text { grain radius } \\
R_{2 D} \\
(\mu \mathrm{m})\end{array}$ & $\begin{array}{l}\text { 3D mean } \\
\text { grain } \\
\text { radius } R_{M} \\
\quad(\mu \mathrm{m})\end{array}$ & $\begin{array}{c}R_{c} \\
(\mu \mathrm{m})\end{array}$ \\
\hline AR & - & $0.28 \pm 0.18$ & $0.0180 \pm 0.0025$ & 2.7 & 4.0 & $10.4 \pm 2.1$ \\
\hline 300 & $2.40 \mathrm{E}+02$ & $0.25 \pm 0.2$ & $0.0163 \pm 0.0023$ & 4.2 & 6.3 & $10.2 \pm 2.6$ \\
\hline 300 & $1.80 \mathrm{E}+04$ & $0.35 \pm 0.35$ & $0.0169 \pm 0.0009$ & 4.8 & 7.2 & $13.8 \pm 2.2$ \\
\hline 300 & $6.05 \mathrm{E}+05$ & $0.56 \pm 0.22$ & $0.0164 \pm 0.0030$ & 7.8 & 11.7 & $22.8 \pm 2.1$ \\
\hline 400 & $2.40 \mathrm{E}+02$ & $0.355 \pm 0.25$ & $0.0095 \pm 0.0037$ & 5.6 & 8.5 & $24.9+4.0$ \\
\hline 400 & $6.48 \mathrm{E}+04$ & $0.56 \pm 0.23$ & $0.0177 \pm 0.0059$ & 10.7 & 16.1 & $21.1 \pm 2.4$ \\
\hline 400 & $6.05 \mathrm{E}+05$ & $0.7 \pm 0.47$ & $0.0166 \pm 0.0062$ & 18.9 & 28.3 & $28.1 \pm 4.1$ \\
\hline 450 & $2.40 \mathrm{E}+02$ & $0.44 \pm 0.3$ & $0.0258 \pm 0.0032$ & 10.4 & 15.6 & $11.3 \pm 2.3$ \\
\hline 450 & $7.92 \mathrm{E}+04$ & $0.87 \pm 0.48$ & $0.028 \pm 0.0053$ & 17.0 & 25.5 & $20.7 \pm 2.7$ \\
\hline 450 & $4.54 \mathrm{E}+05$ & $1.18 \pm 0.64$ & $0.0316 \pm 0.0172$ & 24.0 & 35.9 & $24.9 \pm 3.8$ \\
\hline
\end{tabular}

